\title{
Mapping Long-Term Spatiotemporal Dynamics of Pen Aquaculture in a Shallow Lake: Less Aquaculture Coming along Better Water Quality
}

\author{
Juhua Luo ${ }^{1,2}{ }^{2}$, Ruiliang Pu ${ }^{2}$, Ronghua Ma ${ }^{1}$, Xiaolong Wang ${ }^{1}$, Xijun Lai ${ }^{1}$, Zhigang Mao ${ }^{1}$, \\ Li Zhang ${ }^{3}$, Zhaoliang Peng ${ }^{1}$ and Zhe Sun ${ }^{1}$ \\ 1 Key Laboratory of Watershed Geographic Sciences, Nanjing Institute of Geography and Limnology, \\ Chinese Academy of Sciences, Nanjing 210008, China; rhma@niglas.ac.cn (R.M.); \\ wangxl@niglas.ac.cn (X.W.); xjlai@niglas.ac.cn (X.L.); zgmao@niglas.ac.cn (Z.M.); zlpeng@niglas.ac.cn (Z.P.); \\ sunzhe18@mails.ucas.ac.cn (Z.S.) \\ 2 School of Geosciences, University of South Florida, Tampa, FL 33620, USA; rpu@usf.edu \\ 3 Key Laboratory of Digital Earth Science, Aerospace Information Research Institute, \\ Chinese Academy of Sciences, Beijing 100094, China; zhangli@radi.ac.cn \\ * Correspondence: jhluo@niglas.ac.cn
}

Received: 14 April 2020; Accepted: 5 June 2020; Published: 9 June 2020

\begin{abstract}
Pen aquaculture is the main form of aquaculture in some shallow lakes in eastern China. It is valuable to map the spatiotemporal changes of pen aquaculture in eutrophic lakes to assess its effect on water quality, thereby helping the relevant decision-making agencies to manage the water quality (WQ) of lakes. In this study, an automatic approach for extracting the pen aquaculture area was developed based on Landsat data. The approach integrates five algorithms, including grey transformation, discrete wavelet transform, fast Fourier transform, singular value decomposition and k-nearest neighbor classification. It was successfully applied in the automatic mapping of the pen aquaculture areas in Lake Yangcheng from 1990 to 2016. The overall accuracies were greater than $92 \%$. The result indicted that the practice of pen aquaculture experienced five stages, with the general area increasing in the beginning and decreasing by the end of the last stage. Meanwhile, the changes of nine WQ parameters observed from 2000 to 2016, such as ammonia $\left(\mathrm{NH}_{3}-\mathrm{N}\right), \mathrm{pH}$, total nitrogen (TN), total phosphorus (TP), chlorophyll $a$, biochemical oxygen demand (BOD), chemiluminescence detection of permanganate index (CODMn), Secchi disk depth (SDD) and dissolved oxygen (DO), were analyzed in the lake sectors of Lake Yangcheng, and then their relationships were explored with the percentage of pen aquaculture area. The result suggested that the percentage of pen aquaculture area exhibits significantly positive correlations with $\mathrm{NH}_{3}-\mathrm{N}, \mathrm{TN}$, TP, chlorophyll $a$, BOD and CODMn, but significantly negative correlations with SDD and DO. The experimental results may offer an important implication for managing similar shallow lakes with pen aquaculture expansion and water pollution problems.
\end{abstract}

Keywords: pen aquaculture; water quality; remote sensing; total nitrogen (TN); total phosphorus (TP)

\section{Introduction}

China is the largest inland fishery producer in the world with a proportion of $54.5 \%$ of the global inland fishery production in 2012 (FAO, 2014). Lake aquaculture is an important food source and one of the most popular industries in China [1]. In China, the area of lake aquaculture accounts for $39.4 \%$ of inland aquaculture area based on a 5-year average area from 2006 to 2010 [2]. Pen aquaculture is the main form of aquaculture in shallow lakes [2]. It shifted from a traditional aquaculture with a natural-food based extensive culture in the 1980s and 1990s to a modern aquaculture with a high-density, 
feed-based and intensive culture [3,4]. Compared with traditional aquaculture, pen aquaculture has high production and profitability, and thus has expanded fast since the 1990s in most of the shallow lakes. However, the rapid expansion of pen aquaculture also led to a serious water pollution problem and became one of the major driving factors of eutrophication in most of the shallow lakes in eastern China [3,5-10].

Lake Yangcheng is a representative pen aquaculture shallow lake in eastern China. It is also an important drinking water source for Suzhou District, Jiangsu Province, China. The lake, named "the home of Chinese hairy crab cuisine", is famous for producing high-quality cultivated Chinese mitten crab (Eriocheir sinensis, CMC), a well-known food in China [10-12]. In Lake Yangcheng, CMC is commonly cultivated in pens [13]. The lake produced approximately 2000 tons/year of CMC, with an economic output exceeding 300 million Yuan/year in recent years [11,14]. Therefore, the CMC cultivation has become an economic pillar industry in the region. However, over the years, excessive pelleted feed, fish feces and soluble excretions enriching nitrogen and phosphorus in the pen enclosures have led to the deterioration of the water quality and lake eutrophication [2,9,15-17]. Consequently, the nutrient levels in the lake were much higher than the surface water quality criteria of Class III (total nitrogen (TN) of $1.0 \mathrm{mg} / \mathrm{L}$; total phosphorus (TP) of $0.05 \mathrm{mg} / \mathrm{L}$ ) for a drinking water resource, according to the Environmental Quality Standards for Surface Water (GB 3838-2002) (MEPPRC 2002). It has aroused a major concern from the Ministry of Agriculture and Environmental Protection of China and local governments, and thus they made some legislations to restrict the pen culture area and urged farmers to remove a certain amount of pen aquaculture in order to improve the water quality and protect the water from further deterioration and eutrophication. However, it was not clear what spatiotemporal changes in the pen aquaculture area in Yangcheng Lake have occurred, and whether the government measures to restrict the pen aquaculture removal was effective for improving the water quality. Therefore, it is necessary to determine the location of and area changes in pen aquaculture, as well as the changes in the water quality parameters for a long time series, to assess the effect of pen aquaculture on water quality in order to offer guidance for decision-makers in managing pen aquaculture and restoring the water quality in lakes.

A traditional method for measuring the spatial extent of pen aquaculture is using surveying equipment or Global Positioning Systems (GPS) $[18,19]$. In small shallow lakes with only a few pens, it is feasible and accurate to survey their area and locations by ship-borne GPS measurements. However, in large lakes with hundreds or thousands of pens, it is difficult to obtain measurements of pen aquaculture with a ship-borne GPS due to the high cost [20]. More importantly, the method of ship-borne GPS measurements cannot track historical records of pen aquaculture. Satellite remote sensing is an effective tool to track the spatial distribution and historical change of many water properties, such as aquatic vegetation cover and chlorophyll $a$, with a relative low cost $[18,21-25]$. With an increasing concern about aquaculture's effect on the environment, different moderate- and high-resolution satellite data, such as IKONOS, QuickBird, Worldview, China's satellite ZiYuan-3 and GaoFen-1 and Landsat-5/8 [19,26-29], as well as SAR data, such as RADARSAT SAR and Sentinel-1, have been utilized for mapping aquaculture facilities, including cages, raft pens and ponds in different coastal areas, estuaries and inland lakes [30-32]. Various classification methods have been developed for mapping the aquaculture facilities based on different satellite data, including visual interpretation of the enhanced images, object-oriented classification and decision-tree classification [20,33-37]. However, most existing methods for extracting aquaculture facilities rely on one or more classification features and corresponding thresholds. The thresholds are frequently obtained by training or manual adjustment, and thus they are only appropriate to particular images for extracting the aquaculture facilities. Due to the effects of different environmental conditions, when applying them to other images, their accuracy and reliability would not be ensured from an application viewpoint. Therefore, developing an approach that is able to automatically determine thresholds and extract pen facility information, using long time-series remote sensing images, is important to map the lake area used for pen aquaculture and to monitor its spatiotemporal change over a large area. 
Therefore, the main goal of this study is to develop an automatic approach for mapping time series pen aquaculture areas based on Landsat data, and then to assess their effect on water quality by combining the long-term and site-specific water quality observation data from Lake Yangcheng. The corresponding specific objectives include (i) developing an automatic and robust approach to map pen aquaculture areas in Lake Yangcheng from 1992 to 2016; (ii) exploring correlations between the percentage of pen aquaculture area and water quality parameters; and (iii) assessing the effectiveness of government measures implemented at various stages for controlling pen aquaculture activities to improve water quality.

\section{Materials and Methods}

\subsection{Study Site}

Lake Yangcheng is located in the northeast of the Lake Taihu basin, near the city of Suzhou, Jiangsu Province, China $\left(31^{\circ} 21^{\prime}-31^{\circ} 30^{\prime} \mathrm{N}\right.$ and $\left.120^{\circ} 39^{\prime}-120^{\circ} 51^{\prime} \mathrm{E}\right)$ (Figure 1). It is the third largest freshwater shallow lake in the Lake Taihu basin with a water surface area of approximately $108 \mathrm{~km}^{2}$ and an average depth of $2.1 \mathrm{~m}$. Two nearly parallel narrow strips of land divide the lake into three sectors with limited interconnection channels, named the Western Lake, Central Lake and Eastern Lake, with a water surface area of approximately $32.5 \mathrm{~km}^{2}, 33.6 \mathrm{~km}^{2}$ and $42.1 \mathrm{~km}^{2}$, respectively. In Lake Yangcheng, there are many inflowing and outflowing rivers (Figure 1). According to multi-year observations, the inflowing water is generally from north to south and from west to east; its retention time is 0.38 year [38].

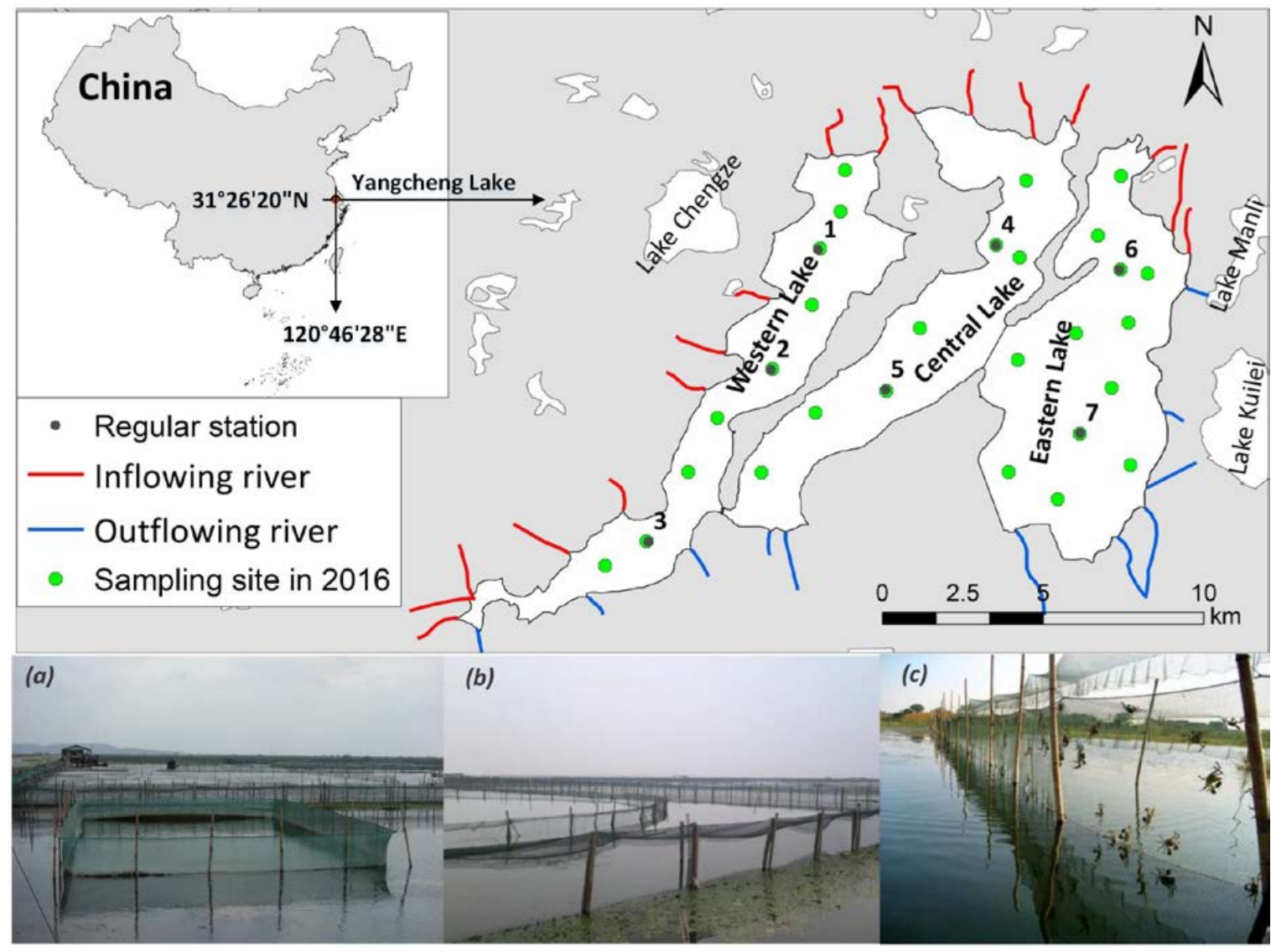

Figure 1. Study area (i.e., Lake Yangcheng, including the Western, Central and Eastern Lakes) and sampling stations/sites location map and site photos of pen aquaculture $(\mathbf{a}-\mathbf{c})$. 
Lake Yangcheng is a representative lake with pen aquaculture of CMC in China. Each pen in the lake, made of $2-3 \mathrm{~cm}$ stretched mesh polythene netting tied to a bamboo framework, covers an area of about 1.3 ha with a length of about $130 \mathrm{~m}$ and a width of $100 \mathrm{~m}$. The bamboo poles $(8-10 \mathrm{~cm}$ in diameter and 4-5 $\mathrm{m}$ in length) of the framework are vertically inserted $60-100 \mathrm{~cm}$ into the bottom of the lake at intervals of 1.5-2.0 m [16]. According to field surveys and inquiries, CMC is the dominant cultured species in the pens due to its high demand and profit. The crabs are fed with artificial pelleted feeds supplemented with vegetable feeds (e.g., corn, wheat and pachyrhizus) and feeds of animal origin (e.g., trash fish) [11].

\subsection{Data}

\subsubsection{Landsat Image Data}

Given the recognizable enclosure size, data consistency and traceability, we used Landsat Thematic Mapper (TM), Enhanced Thematic Mapper Plus (ETM+), and Operational Land Imager (OLI) with a long time-series record and a spatial resolution of $30 \mathrm{~m}$ to extract the pen aquaculture area and monitor its spatiotemporal change. In this study, a total of 26 scenes of cloud-free Landsat TM/ETM+/OLI images acquired from 1991 to 2016 were collected from the U.S. Geological Survey (USGS, https://earthexplorer.usgs.gov) (Table A1). The collected images were acquired only between April and May because of the following reasons: (i) Since image spectral features of the pen facility are similar to the aquatic vegetation, especially floating-leaved vegetation, the image acquisition chosen in April or May can avoid such a confusion of spectral features between the pen facility and aquatic vegetation [39]. (ii) Crab seeds are transferred to aquaculture pens between mid-February and mid-April and are harvested at the end of October every year. Some pen facilities are removed or broken from November to the next February [10]. (iii) Some algae particles and budding floating-leaved vegetation float and aggregate around the pen facilities between April and May, which makes the spectral feature of the pen more significant from its background, and thus the information about the pen facility is easier to be extracted than that in the other months (Figure 1b). In addition, since there were no available Landsat data in April and May in 2012 and 2014 (Table A1), Huangjing Charge Coupled Device (HJ CCD) images were used as the supplementary data to map the pen aquaculture in the two years. HJ-CCD images were acquired from the China Centre for Resources Satellite Data and Application (CRESDA). HJ-1A/1B CCD has a similar spectral band setting and spatial resolution to those of the first four bands of Landsat TM. Previous studies indicated that the data had a good consistency with Landsat data in application [40,41].

In order to develop an automatic method for extracting the pen aquaculture area, we chose a Landsat OLI image acquired on 22 May 2015, as a test image, and a high-resolution image called ZiYuan-3 (ZY-3) acquired on 28 April 2015, as a reference image. The ZY-3 satellite, launched in January 2012, is China's first civilian high-resolution optical satellite. It provides four multispectral (MS) bands with a spatial resolution of $5.8 \mathrm{~m}$ and a revisit cycle of 5 days. We visually interpreted the pen aquaculture area from the reference image to validate the result of the pen aquaculture area mapped from the test image.

\subsubsection{Water Quality Data}

We collected two datasets of water quality (WQ) data, including nine WQ parameters, namely, dissolved oxygen (DO), biochemical oxygen demand (BOD), $\mathrm{pH}$, ammonia $\left(\mathrm{NH}_{3}-\mathrm{N}\right)$, total nitrogen (TN), total phosphorus (TP), chlorophyll $a$ (Chla), Secchi disk depth (SDD) and chemiluminescence detection of permanganate index $\left(\mathrm{COD}_{\mathrm{Mn}}\right)$. We defined the two datasets as Dataset A and Dataset $\mathrm{B}$. Dataset A was provided by the Suzhou water environment monitoring department. Monthly WQ parameters were measured from seven regular stations from 2000 to 2016, except for 2001 and 2002. The seven regular stations, including three stations in Western Lake, two stations in Central Lake and two in Eastern Lake, were set according to the spatial variability of the WQ in the three lakes 
(Figure 1). The average WQ at these stations in every lake could be roughly representative of the overall WQ state of the corresponding lakes. Dataset B was collected from 27 sampling sites in 2016, including eight sites in Western Lake, seven sites in Central Lake and 12 sites in Eastern Lake (Figure 1). All the WQ parameters from the two datasets were measured using standard methods. SDD, $\mathrm{pH}$ and DO were directly measured in the field, while $\mathrm{TN}, \mathrm{NH}_{3}-\mathrm{N}, \mathrm{TP}, \mathrm{COD}_{\mathrm{Mn}}$ and Chla were measured in the laboratory from samples collected from stations/sample sites. TP was determined by using ammonium molybdate spectrophotometry (GB11893-89), whereas TN was determined via alkaline potassium persulfate digestion and UV spectrophotometry (GB11894-89). CODMn was determined using the acidic potassium permanganate method (GB/T11892-89). $\mathrm{NH}_{3}-\mathrm{N}$ was determined using Nessler's reagent method (GB 7479-87), spectrophotometry and the molybdenum blue technique (GB 11893-89). In this study, based on Dataset A, we averaged the monthly WQ observations from Stations 1, 2 and 3 in Western Lake, Stations 4 and 5 in Central Lake, and Stations 6 and 7 in Eastern Lake, and then averaged them across 12 months to obtain an annual average of each lake sector for the correlation analysis with their corresponding pen aquaculture area. For the TN and TP observations from the seven stations in 2016, the spatial and seasonal variations in WQ parameters varied from the different stations (Figure A1). Generally, there was the highest TN and TP concentration in Western Lake (Stations 1, 2 and 3), followed by Central Lake (Stations 4 and 5), and the lowest in Eastern Lake (Stations 6 and 7).

In addition, to explore the nutrient source in the three lake sectors, in 2016, monthly discharges of the inflow and outflow rivers surrounding the lakes were monitored in situ with an acoustic Doppler current profiler (Sontek, RiverSurveyor M9, SonTek, San Diego, CA, USA), and the corresponding TN and TP concentrations were also measured using standard lab measurement methods described above. Finally, the seasonal fluxes of TN and TP were calculated by multiplying the seasonal discharge and corresponding concentrations of TN and TP.

\subsection{Methods}

\subsubsection{Feature Image Selection for Extracting Pen Aquaculture}

In the Landsat test image, we first selected a sample line, including pixels of the pen aquaculture facility, water and aquatic vegetation, and then plotted the pixels' values of the blue, green, NIR and SWIR bands. Pixels of the pen facility have the greatest spectral difference from other objects in the NIR band (Figure 2), and thus the NIR image might be selected as the sensitive feature image from which to extract the pen aquaculture information.

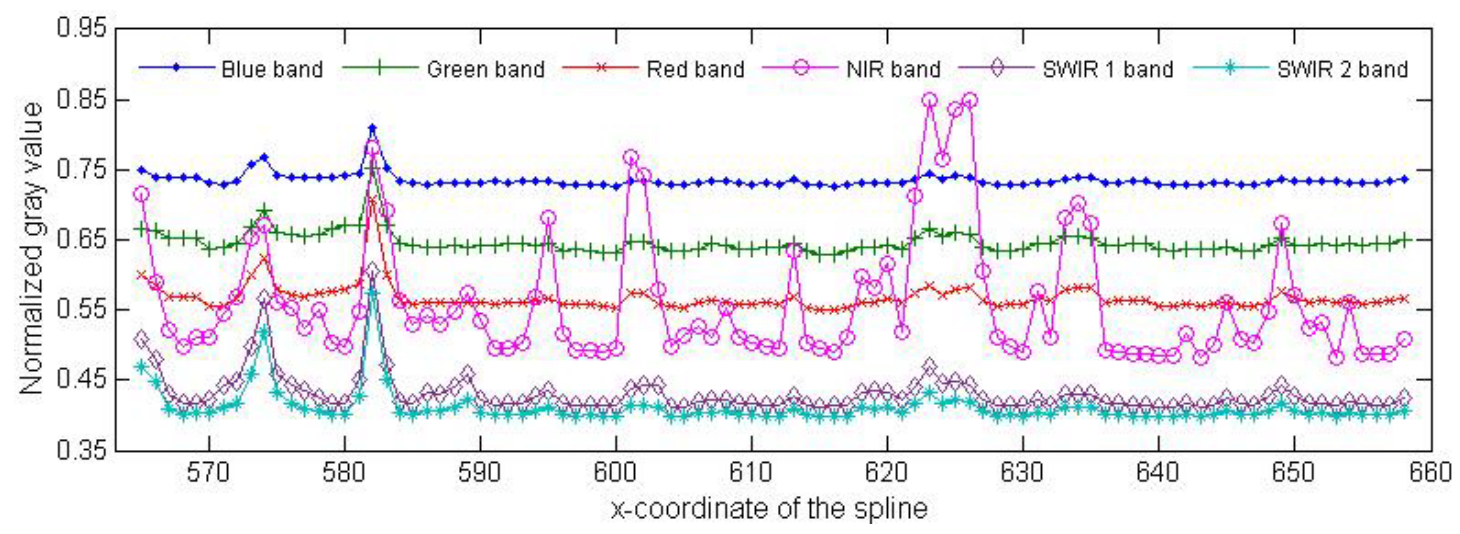

Figure 2. Pixel grey values of the different bands from a sample line, including pen facility and water, etc. 


\subsubsection{Extraction of Pen Aquaculture Information}

The pen aquaculture area was extracted based on four steps, including image enhancement, image segmentation, feature extraction and target classification. Specifically, the procedures consist of five algorithms: grey transformation (GT), discrete wavelet transform (DWT), fast Fourier transform (FFT), singular value decomposition (SVD) and $k$-nearest neighbor $(\mathrm{kNN})$ classification.

All algorithms were written and executed using MATLAB software, and some functions, including $\mathrm{fft}()$, wavedec () and svd (), were directly called in MATLAB when conducting the DWT, FFT and SVD algorithms.

Detailed algorithms and steps are described as follows:

1. Image enhancement. Image enhancement is a process of adjusting the digital images to make a target (i.e., pen aquaculture area) easier to be identified. There are two steps, including image normalization and exponential GT, to enhance the image and highlight the pen facility [42]. The formula is as follows:

$$
\begin{gathered}
N(x)=F(x) / F(m) \\
G(x)=N(x)^{0.3}
\end{gathered}
$$

where $N(x)$ is the pixel value on a normalization image; $F(x)$ is the pixel value on a feature image; $F(m)$ is the maximum pixel value in the feature image; and $G(r)$ is the transformed pixel value of the corresponding normalized image.

2. Image segmentation. It was critical to automatically acquire an appropriate threshold for segmenting an image and identifying a target. Considering noise in the image after GT processing, it was relatively difficult to obtain an appropriate threshold for segmenting an image. In this study, a DWT was applied to remove noise and then to determine the corresponding thresholds $[43,44]$. The DWT transform can be expressed as follows:

$$
w_{f(a, b)}=\left\langle f(x), \psi_{(a, b)}(x)\right\rangle=\left|a_{0}\right|^{\frac{-m}{2}} \int_{-\infty}^{+\infty} f(x) \overline{\psi\left(a_{0}^{-m} t-n b_{0}\right) d x}
$$

where $f(x)$ is the histogram of the grey-level transformation image; $a$ is the scaling factor determining the width of the wavelet; $b$ is the shifting factor indicating the position of a mother wavelet; and $\psi_{(a, b)}(x)$ represents the wavelets that are transformed by scaling and shifting the mother wavelet $\psi(x)$. In this study, $a_{0}=2, b_{0}=1$ and the mother wavelet $\psi(x)$ was $\mathrm{db} 4$.

In this study, after the wavelet was reconstructed, a threshold for segmenting water and other objects could be identified and determined by finding out the first turning point to the left of the highest peak. Then the turning point was the threshold.

3. Feature extraction. The pen facility has a similar spectral feature with aquatic vegetation, but it shows a regular shape and periodic spatial arrangement. In practice, an FFT proved to be an effective tool in extracting the time and spatial change frequency of the targets [20]. Therefore, in this study, we used a 2-dimensional discrete FFT (FFT2) to exact the features of the water, aquatic vegetation and different angles of a pen facility. The FFT2 formula is shown as follows:

$$
\begin{aligned}
F(u, v) & =\frac{1}{M N} \sum_{x=0}^{M-1} \sum_{y=0}^{N-1} f(x, y) \exp \left[-j 2 \pi\left(\frac{x u}{M}+\frac{y v}{N}\right)\right] \\
u & =0,1, \ldots, M-1 ; v=0,1, \ldots N-1
\end{aligned}
$$

where $F(u, v)$ is the frequency spectrum of the original image $f(x, y)$. In this study, $f(x, y)$ is a segmented image. 
After FFT2, an SVD was executed to reduce the dimensionality and extract the features of different objects. The SVD provides a convenient way for breaking a matrix, which perhaps contains some data in which we are interested into simpler, meaningful pieces [45]. It is widely used in data compression, noise reduction, etc. It can be used to detect and extract weak signals from noisy data. For an SVD, we begin with an arbitrary really valued $m \times n$ matrix $X$.

$$
\mathrm{X}=\mathrm{USV}^{T}
$$

where $\mathrm{S}$ is the $m \times n$ diagonal matrix; and $\mathrm{V}^{T}$ is the $n \times n$ matrix. The columns of $\mathrm{U}$ and $\mathrm{V}$ are called the left and right singular vectors. In this study, $\mathrm{X}$ is the frequency-domain matrix derived from FFT2, with $m=15$ and $n=15$.

4. Target identification. A kNN rule, one of the classic and top-performing classifiers, was used to identify the pen aquaculture area. It achieves a classification by calculating the similarity between the test sample (pixel) and all the training samples based on a discrimination function [46]. The similarity can be measured by Euclidean distances [47,48]. The discrimination function is as follows:

$$
g_{i}(x)=\min _{k}\left\|x-x_{i}\right\|, k=1,2, \ldots N
$$

where $x_{i}$ is the vector of class $i$ in training set; $x$ is the vector to be unclassified; and $N$ is the number of classes. In this study, there existed water, aquatic vegetation and the pen grids with different angles, which can be generalized as $45^{\circ}, 75^{\circ}$ and $90^{\circ}$.

\subsubsection{Validation of Extracting Result}

Given the lack of actual area data of pen aquaculture, we used the aquaculture distribution area created by visually interpreting the high resolution ZY-3 images as a reference to assess the extracted result from the Landsat test image. We defined the classification map created with the automatic algorithms as Map A and the visual interpretation map as Map B. By overlay analysis, we could get the area in agreement (i.e., the area shown in both Maps A and B), the omission area (i.e., the aquaculture area identified as non-aquaculture area) and the commission area (i.e., the non-aquaculture area identified as aquaculture area) to conduct a spatial accuracy assessment. Further, the overall accuracy as well as the errors of commission and omission could be calculated using the following formulas:

$$
\begin{gathered}
E_{O}=S_{O} / S_{B} \times 100 \% \\
E_{C}=S_{C} / S_{B} \times 100 \% \\
\text { Overall accuracy }=S_{x} / S_{B} \times 100 \%
\end{gathered}
$$

where $E_{O}$ and $E_{C}$ are the errors of omission and commission, respectively; $S_{O}$ and $S_{C}$ are the areas of omission and commission, respectively; $S_{A}$ and $S_{B}$ are the areas of pen aquaculture extracted by the automatic algorithms and visual interpretation, respectively; and $S_{x}$ is the area classified as pen aquaculture shown in both Maps A and B.

Meanwhile, we also collected records of the pen aquaculture area from 2000 (Ding et al. 2015), 2001 (Tang 2010), 2005 (Ji et al. 2018) and 2010 (Huang et al. 2017) as the reference data to further validate our results derived from the Landsat data.

\section{Results}

\subsection{Extraction of Pen Aquaculture Area and Validation}

Pixel grey values of the normalized blue, green, red, NIR, SWIR1 and SWRI2 bands in a sample line, including the typical pen, aquatic vegetation and water pixels (Figure 2). It was significant that 
only the NIR band exhibited significant and periodic peaks of the pen facility compared with all the other five bands. Thus, NIR could be selected as a feature band to extract the pen area.

The NIR image, enhancement image, segmented image and extracted resultant map of the pen aquaculture area are shown in Figure 3. Obviously, the pen grid feature was enhanced and was identified more easily (Figure 3b). However, some noise, including cloud and aquatic vegetation, were also enhanced (e.g., noise within the red circles in Figure 3b). A threshold of 231 was obtained by the DWT and wavelet reconstruction to segment the image (Figure A2). The segmentation image indicated that some noise, such as light cloud (e.g., some noises within the red circles in Figure 3b), were removed by the wavelet transformation, but some noise, such as aquatic vegetation and light cloud (e.g., some noise within the red circles in Figure 3c), were not removed. Finally, the distribution map of pen aquaculture in Lake Yangcheng after FFT (Figure A3) and kNN were obtained (Figure 3d). Obviously, due to FFT2 processing, some vegetation regions without pen facilities but with similar spectral feature as them had been excluded (e.g., vegetated areas within the red circles in Figure 3c).

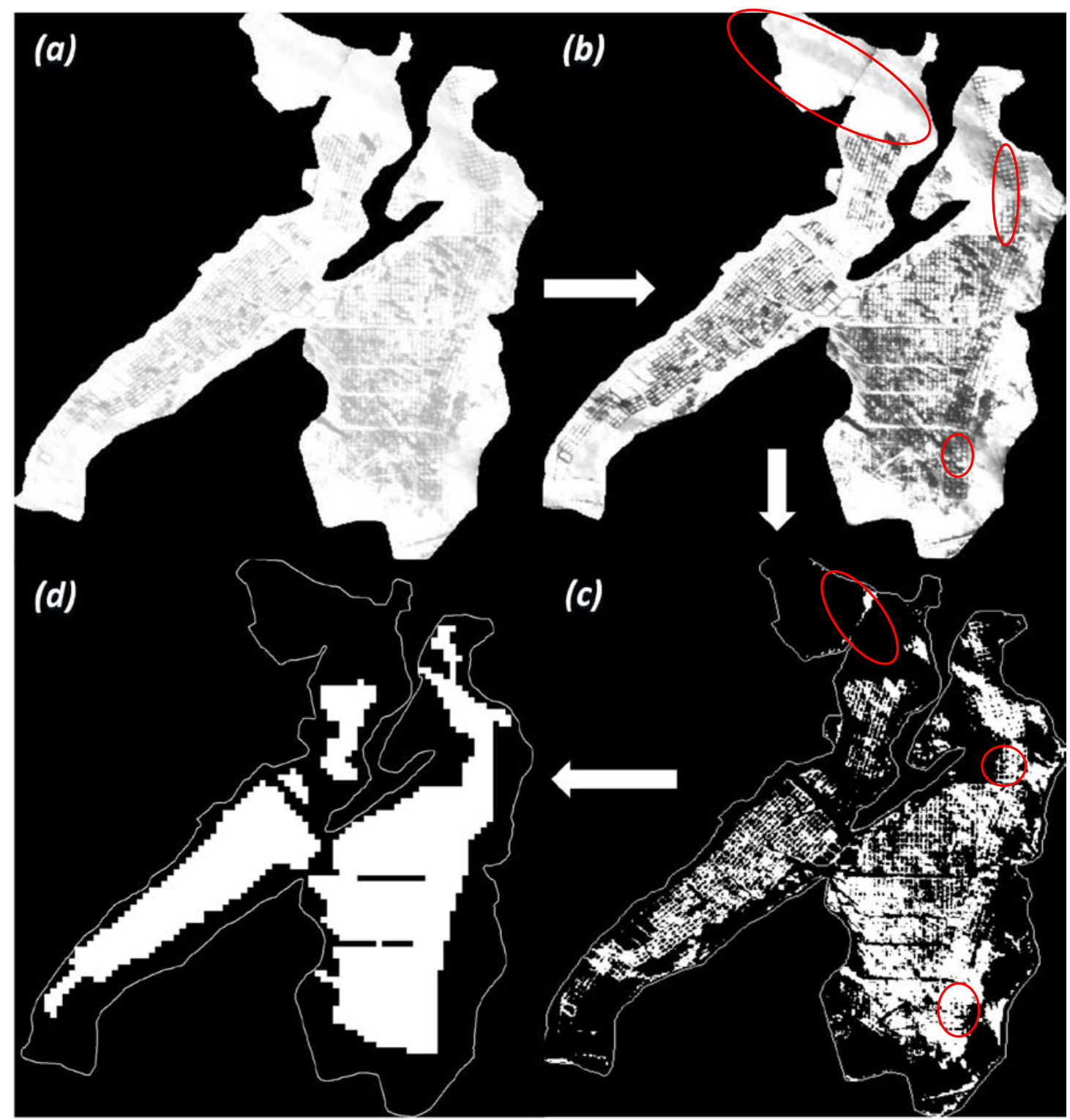

Figure 3. NIR band image (a), enhanced image (b) derived from Equations (1) and (2), segmented image based on Equation (3) (c) and extracted resultant map of pen aquaculture based on Equation (6) (d). The white areas within the red circles are noise (e.g., aquatic vegetation and light cloud). 
The extracted result was transferred into a shapefile (Figure 4a) and compared with the visual interpretation result (Figure $4 \mathrm{~b}$ ) in GIS mapping software. Spatially, most of the omission and commission areas were located along edges of the pen aquaculture. Most of misclassified areas were actually aquatic vegetation with a high coverage (e.g., the area within the yellow circle in Figure 4c). Overall accuracy of the exacted result was $92.95 \%$ with a commission error of $16.72 \%$ and an omission error of $7.05 \%$ (Table 1 ). The relative difference is $-2.46 \sim 4.18 \%$ between the monitoring area of pen aquaculture in 2000, 2001, 2002 and 2015 using the proposed approach and the area recorded in the corresponding reference years (Table 2).
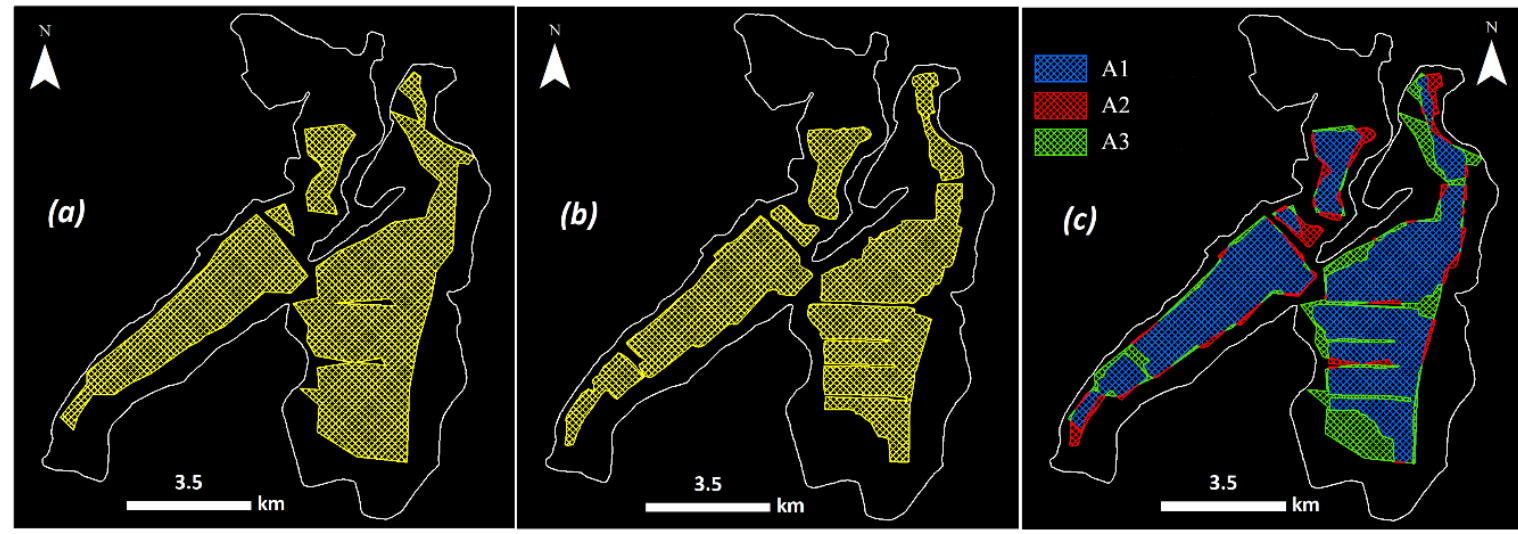

Figure 4. Maps of pen aquaculture created by using the method proposed in this study (a), visual interpretation method (b) and comparison of these two maps (c). A1: Area in agreement; A2: Omission area (i.e., the aquaculture area identified as non-aquaculture area); A3: Commission area (i.e., the non-aquaculture area identified as aquaculture area).

Table 1. Accuracy assessment of the pen aquaculture area extracted.

\begin{tabular}{ccccc}
\hline$S_{B}$ & $S_{A}$ & $S_{C}$ & $S_{O}$ & $S_{x}$ \\
\hline $29.95 \mathrm{~km}^{2}$ & $33.44 \mathrm{~km}^{2}$ & $5.59 \mathrm{~km}^{2}$ & $2.11 \mathrm{~km}^{2}$ & $27.84 \mathrm{~km}^{2}$ \\
\hline \multicolumn{4}{c}{ Overall accuracy } & $=92.95 \% ; E_{C}=16.72 \% ; E_{O}=7.05 \%$.
\end{tabular}

Note: $S_{A}$ and $S_{B}$ are the area by the approach proposed and the visual interpretation method, respectively; $S_{O}$ and $S_{C}$ are the omission area (i.e., the aquaculture area identified as non-aquaculture) and commission area (i.e., the non-aquaculture area identified as aquaculture area), respectively; $S_{x}$ is the area in agreement in both Maps $\mathrm{A}$ and $\mathrm{B}$. $E_{O}$ and $E_{C}$ are the omission error and commission error, respectively.

Table 2. Relative difference between the monitoring area of the pen aquaculture mapped using our approach and the reference areas.

\begin{tabular}{cccc}
\hline Year & Reference Area $\mathbf{( k m}^{\mathbf{2}}$ ) & Monitoring Area $\mathbf{( k m}^{\mathbf{2}}$ ) & Relative Difference (\%) \\
\hline 2000 & 92 (Ding et al. 2015) & 89.79 & -2.46 \\
2001 & 95 (Tang 2010) & 94.37 & -0.67 \\
2002 & 91 (Ji et al. 2018) & 95.03 & 4.24 \\
2015 & 31 (Huang et al. 2017) & 32.05 & 3.28 \\
\hline
\end{tabular}

Note: Relative difference $(\%)=($ Monitoring area - Reference area $) /$ Reference area $\times 100$.

\subsection{Spatiotemporal Changes in Pen Aquaculture from 1992 to 2016}

The spatiotemporal changes in pen aquaculture were different among the three lake sectors from 1992 to 2016 (Figures 5 and 6). In Eastern Lake, the percentage of pen aquaculture area to the whole lake area reached $90 \%$ in 1993 , decreased to $55.80 \%$ in 1994 , then increased to $93.54 \%$, and finally decreased to $40.38 \%$ in 2016. In Central Lake, the percentage increased from $57.42 \%$ in 1993 to $89.95 \%$ in 2014, and then decreased to 37.03\% in 2016. In Western Lake, it increased from 46.08\% in 1993 to $87.64 \%$ in 1998, and then kept unchanged until 2008 when it was removed completely. In general, 
the change process for the entire lake can be categorized into five stages. Stage I was before 1993 when there was not any pen facility there. Stage II was from 1992 to 2002. Pen aquaculture started in 1993 with a percentage of $66.81 \%$, and then increased to $87.71 \%$ in 2002. Stage III was between 2002 and 2007 , at which the proportion of pen aquaculture decreased slightly from $87.71 \%$ in 2002 to $75.86 \%$ in 2007. Stage IV was from 2007 to 2011 when pen aquaculture experienced a sharp decrease from 75.86 in 2007 to $29.32 \%$. At Stage V, it was kept around $28 \%$ from 2011 to 2016.

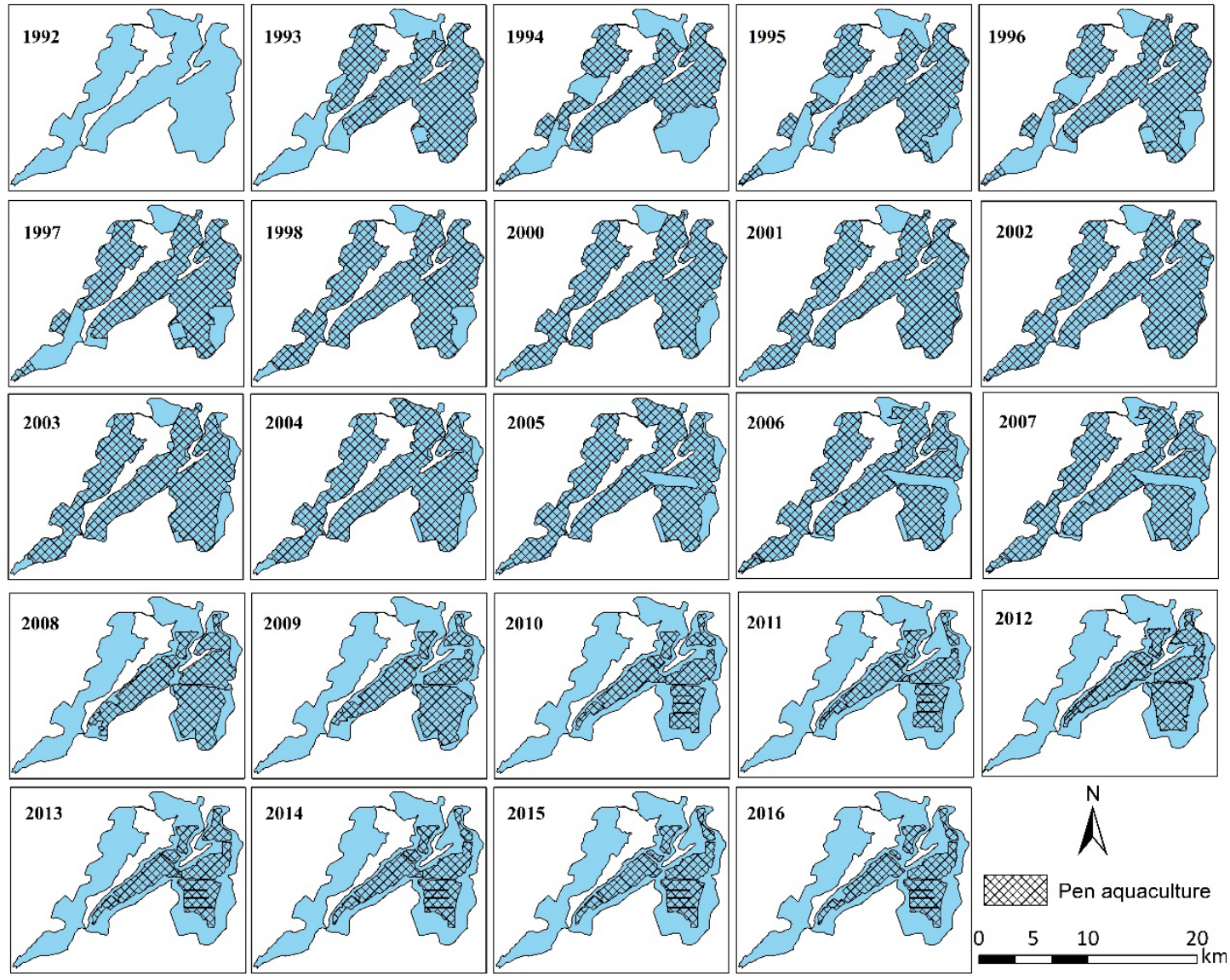

Figure 5. Spatial distribution of pen aquaculture from 1992 to 2016.

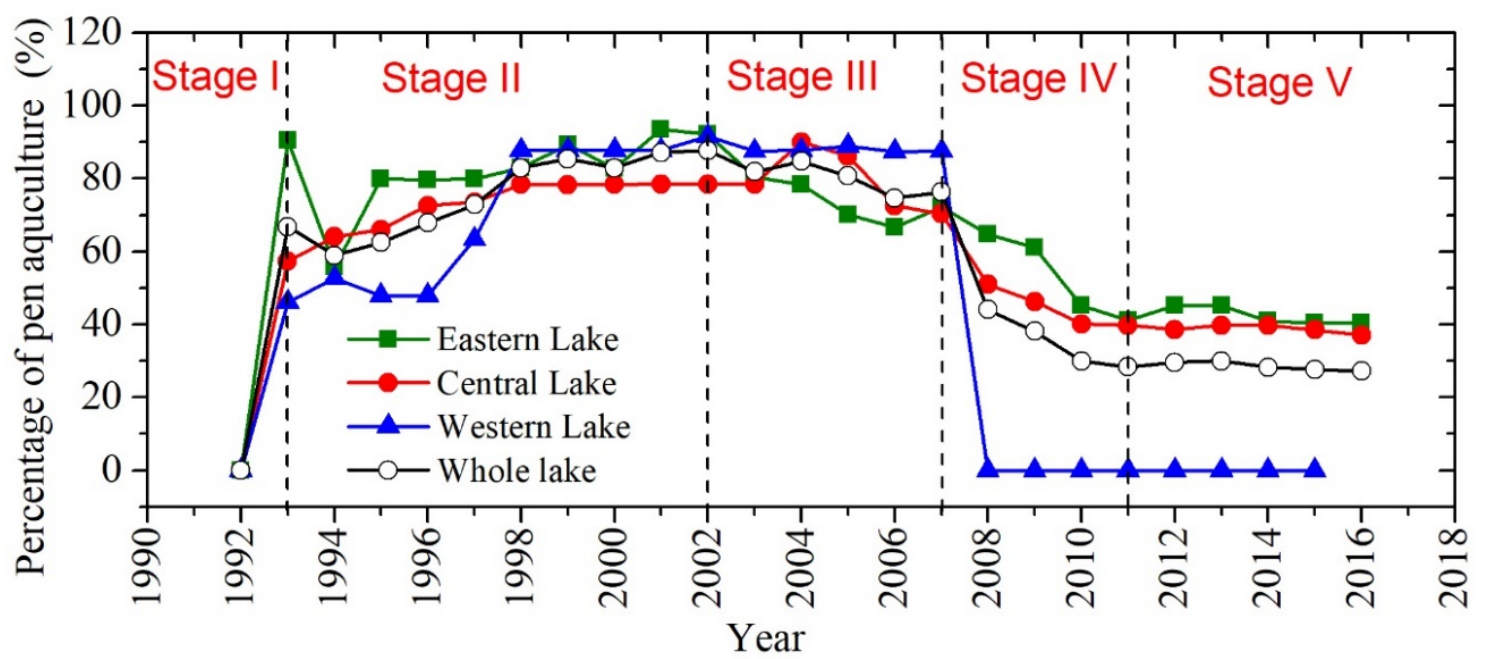

Figure 6. Area changes in pen aquaculture area from 1992 to 2016 in the Western, Central and Eastern Lakes. 


\subsection{Long-Term Trends in Water Quality and Correlations with the Percentage of Pen Aquaculture}

From 2000 to 2016, WQ was improved in the three lake sectors with decreasing $\mathrm{NH}_{3}-\mathrm{N}, \mathrm{TN}, \mathrm{Chla}$,

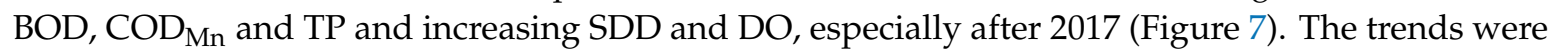
more significant in the Central and Eastern Lakes than Western Lake, and more obvious at Stage IV. WQ was worst in Western Lake, and it was better in Central Lake than Eastern Lake.
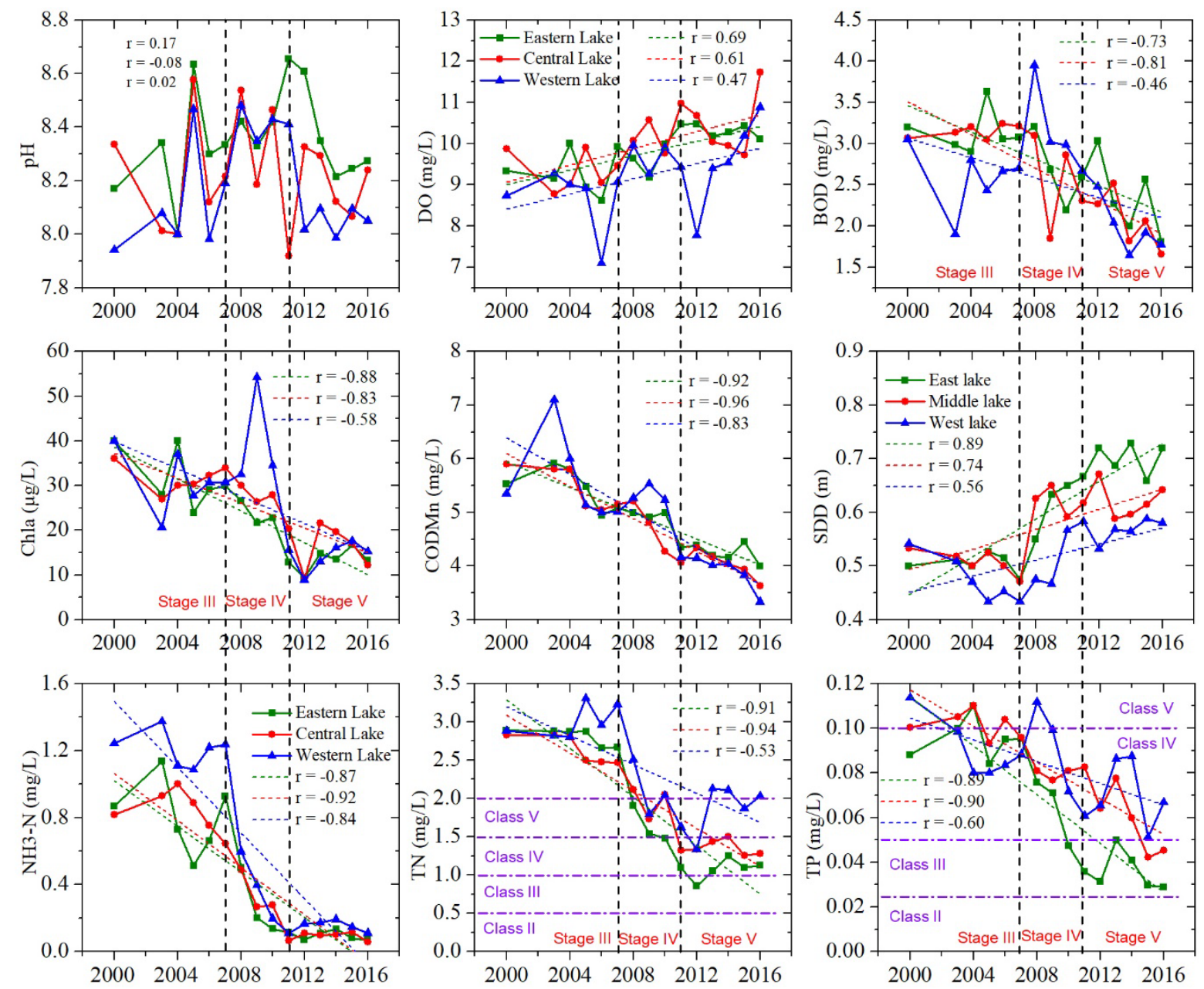

Figure 7. Change trends of water quality parameters from 2000 to 2016 in the Western, Central and Eastern Lakes. The colored dashed lines are trendlines and $\mathrm{r}$ is the correction coefficient. The trendlines were drawn only if the $p$-value $<0.05$. A positive $\mathrm{r}$ and $p$-value $<0.05$ represent a significant increasing trend over time and a negative $\mathrm{r}$ and $p$-value $<0.05$ represent a significant decreasing trend over time. $p$-value $>0.05$ shows no monotonic change.

TN and TP at Stage III severely exceeded the Environmental Quality Standards for Surface Water for Lakes (GB 3838-2002), being lower than the criteria of Class V for TN $(1.5 \leq \mathrm{TN} \leq 2.0 \mathrm{mg} / \mathrm{L})$ and Class V for TP $(0.1 \leq \mathrm{TP} \leq 0.2 \mathrm{mg} / \mathrm{L})$ in the three lake sectors. At Stage IV, TN and TP decreased obviously. TN was Class V and TP was Class IV $(0.05 \leq \mathrm{TP} \leq 0.1 \mathrm{mg} / \mathrm{L})$ in the three lake sectors. At Stage V, TN fluctuated around Class V in Western Lake, Class IV $(1 \leq \mathrm{TN} \leq 1.5 \mathrm{mg} / \mathrm{L})$ in Central Lake and Eastern Lake, while TP kept Class IV in Western Lake and Central Lake, and reached Class III $(0.025 \leq \mathrm{TP} \leq 0.05 \mathrm{mg} / \mathrm{L})$ in Eastern Lake.

$\mathrm{NH}_{3}-\mathrm{N}, \mathrm{TN}, \mathrm{Chla}, \mathrm{BOD}, \mathrm{COD}_{\mathrm{Mn}}$ and TP had significant positive correlations with the percentage of pen aquaculture area; SDD and DO showed significant negative correlations with the percentage of pen aquaculture area; and $\mathrm{pH}$ showed no correlation with the percentage of pen aquaculture area (Figure 8). 

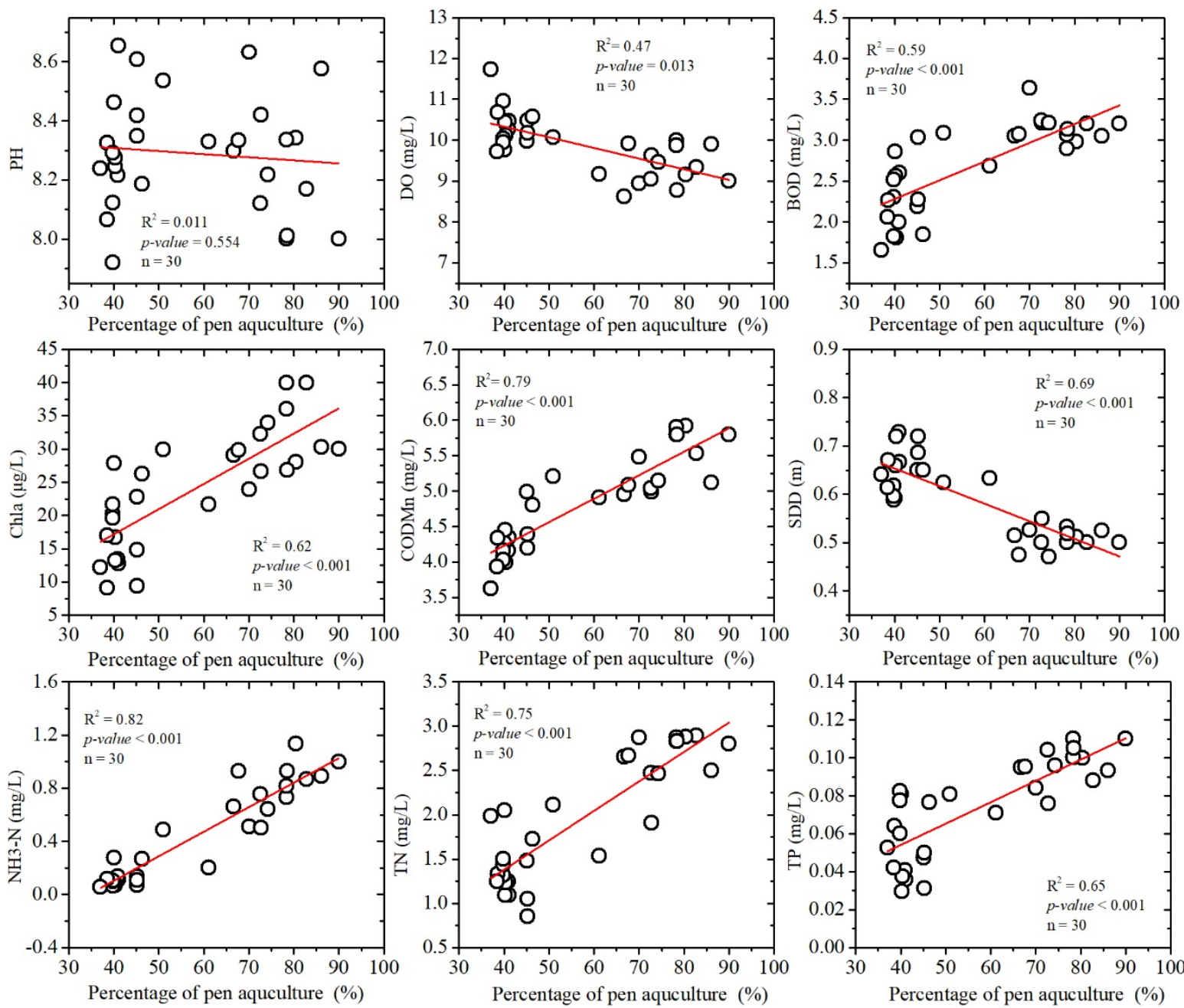

Figure 8. Correlations between the percentage of pen area and water quality parameters in the Central and Eastern Lakes. It excludes the Western Lake because there has been no pen in Western Lake since 2007.

\section{Discussion}

\subsection{Advantages and Uncertainty of the Proposed Approach}

Satellite remote sensing has been proved to be an effective tool to map aquaculture distribution at a large scale $[19,26,28,29,31,49]$. Sensitive image features of the aquaculture facilities (e.g., cages and pens) and classification methods are key in mapping an aquaculture area. In this study, the NIR band was proved to be more sensitive to pen facilities than other bands (Figure 2), and thus effective in mapping the pen facilities. This is because of the amount of floating-leave vegetation and algae particles that aggregate around the pen facilities (due to wind and waves) (Figure 1b) during the image acquisition time (i.e., between April and May), which make the pen show a significant vegetation spectral feature (i.e., the high reflection in the NIR band and strong absorption in the Red band). In addition, although there exist a few methods for mapping aquaculture facilities (e.g., cages and pens), they have disadvantages and limitations. For example, an object-oriented image analysis is a very commonly used method for extracting aquaculture facilities due to their regular shapes and special locations $[33-37,50,51]$. However, the determination of thresholds of the feature parameters relies on interested image features and manual checking. The threshold determined for one time period or a specific image could be inadequate when applied to other dates or images due to different influences, including water properties, atmospheric conditions, sun-view geometry, etc. [52]. Therefore, 
when using time-series Landsat data to extract the change information of pen aquaculture, the existing methods are inefficient because of the low degree of automation. Compared with the existing methods, our approach could offer an effective solution for finding out the appropriate thresholds for different images acquired in different dates to automatically map pen aquaculture, and thus it has a large potential in tracking the spatiotemporal changes of pen aquaculture area using time-series satellite images without manual intervention. The proposed approach included (i) automatically determining the thresholds for segmenting water and other objects by using DWT; (ii) extracting the identification features of the water, aquatic vegetation and pen facility according to their intrinsic attributes and shape characteristics using FFT and SVD; and (iii) automatically mapping pen aquaculture area by using the $\mathrm{kNN}$ rule based on these identification features.

When executing the approach to other lakes or images, the following few points and limitations should be noted: (i) the approach is only suitable for mapping pen aquaculture area using images acquired from April to May (see the detailed reasons in Section 2.2.1); (ii) for images with different spatial resolutions, some parameters for the algorithms need to be adjusted and modified, such as an appropriate matrix size involving the number of pixels containing a regular pen input in the algorithms of FFT2 and SVD; (iii) the algorithms included in our approach are not unique, and others with the same functions might be more appropriate due to different images and sites condition. For example, the GT method for highlighting a pen facility in visual can be replaced by other image enhancement methods, such as a gradient transform [53]. A Gaussian fitting also may be used to replace WT to remove the noise and find a threshold [54].

\subsection{Main Factors Affecting Water Quality in Lake Yangcheng}

Generally, excess nitrogen $(\mathrm{N})$ and phosphorus $(\mathrm{P})$ loading from the point and non-point sources in a watershed are considered as one of the main factors damaging the ecological quality of lakes $[38,40,55]$. In Lake Yangcheng, besides the external nutrient loadings such as industrial effluents and agriculture non-point sources, intensification through increasing use of pelleted feeds and the expansion of pen aquaculture area was another main factor inducing lake eutrophication and deteriorating of WQ [2]. The amount of food fed to the crabs depends on the growth stages of the crab, water quality, temperature and so on. Approximately $0.8 \mathrm{~kg}$ of food per acre is put into the pen at the beginning of crab growth, and it will be increased at $10 \%$ every three days. About $1 / 3$ of the feed nutrients are consumed by fish and the $\mathrm{CMC}$, with the remaining being released into the immediate environment $[5,8]$. The excessive pelleted feed and aquaculture wastes, including residual solid feed, fish (or crab) feces and soluble excretions enriching nitrogen and phosphorus, could result in or aggravate lake eutrophication [15,17].

Exchange of nutrients between a lake and watershed is performed through inflowing and outflowing rivers. In Lake Yangcheng, the inflowing rivers are distributed in the west and north lines, and outflowing rivers in the south and east lines (Figure A4a). According to the field surveys and measurements in 2016, about 4765.12 tons TN and 331.08 tons TP were inflowed into Western Lake from the west line, and the loading amounts of TN and TP were about 142.24 ton $/ \mathrm{km}^{2}$ and $9.88 \mathrm{ton} / \mathrm{km}^{2}$, respectively. In addition, there was no pen aquaculture in the lake. Consequently, in Western Lake, the poor WQ and high nutrients might be mainly caused by nutrient loadings from the corresponding watershed, which might explain why Western Lake had the worst WQ although the pens had been removed since 2008 (Figure 7). Water quality of the Western Lake has been improved since 2008, even though it was still the worst among the three lake sectors (Figures 5 and 7). Besides removing the pen aquaculture in the lake, in the corresponding watershed, a series of other measures have been also taken in order to reduce the nutrient loading into the lake, such as removing or closing hundreds of the heavy polluting enterprises and restaurants along with the lake, shrinking the aquaculture pond area, intensifying and improving sewage treatment, etc. These measures made contributions to nutrient reductions in the inflow and water quality improvement of the lakes. In Central and Eastern Lakes, about 640.17 tons TN and 56.091 tons TP inflowed into the lakes from the north line, and the loading amounts of TN and TP were about $8.45 \mathrm{ton} / \mathrm{km}^{2}$ and $0.91 \mathrm{ton} / \mathrm{km}^{2}$, respectively. They only account for 
1/17 of the loading amounts of TN and 1/10 of the TP in Western Lake. However, given its retention time of only 0.38 year and the interconnection of the three lake sectors, it is difficult to quantify and separate nutrient contributions from pen aquaculture and from the surrounding area in the two lakes based on the limitations of the existing data we collected. However, pen aquaculture activities certainly could have a negative effect on water quality in Lake Yangcheng because the TN and TP inside the pens were always higher than those outside the pens in both lake sectors (Figure A5). In the future, based on multi-source data, including survey data of watershed pollution sources, detailed nutrient measurements and simulations inside and outside lakes, as well as the pen areas being mapped by our approach, etc., it is possible to develop an integrated model for quantitatively estimating the contribution rate of each source.

\subsection{Effects of Pen Aqauculture Govermance}

The pen aquaculture area in Lake Yangcheng experienced five change stages, as illustrated in Figure 7. Change trends of TP and TN showed a similar trend with those of pen aquaculture area percent in Central and Eastern Lakes (Figure 9). Their changes were closely related to local government measures from Stages III to V. At Stage I, there was no pen facility in the lakes and traditional aquaculture with natural food, such as grass carp and aquatic vegetation, and the corresponding water quality state was not clear due to the lack of corresponding WQ observation data. At Stage II, pen aquaculture started and then fast expanded without any measure and reached its peak (Figure 9). At this stage, because of the high production from pen aquaculture, the economic profitability was paid too much attention instead of considering the deterioration of the WQ. Consequently, in 2000, the mean TN level reached the surface WQ criteria of Class V (TN $\geq 2.0 \mathrm{mg} / \mathrm{L})$ and the TP level was almost Class IV (TP $\geq 0.1$ ). At Stage III, the WQ parameters were at the worst levels, and the TP and TN levels kept at Class IV and Class V, respectively. The deterioration of the WQ induced a considerable concern by the Suzhou Fisheries Bureau, and they proposed that pen aquaculture in Lake Yangcheng should be shrunken to $40 \%$ of the water surface area, and it was approved by the Standing Committee of the People's Congress of Jiangsu Province in 2004. From Figures 6 and 9, we see that pen aquaculture experienced only a slight decrease in the Central and Eastern Lakes from 2004 to 2007. Stage IV was located at an important transition of pen aquaculture area. Due to a major pollution event, an algae bloom outbreak in Lake Taihu in 2007, the Jiangsu Province Water Resources Department and Ocean and Fisheries Bureau jointly issued a proposal about controlling water pollution in the Taihu basin involving Lake Yangcheng and undertook unprecedented efforts to compulsively remove pen aquaculture in some lakes in the Taihu basin. For example, the extent of pen culture area in East Taihu Lake had been reduced from 11,267 ha to 3000 ha in 2009. Obviously, those efforts made a significant effect on improving the WQ (Figures 7 and 9). The total percentage of pen aquaculture in the Central and Eastern Lakes declined fast, from 80\% in 2007 to 32\% in 2010, and all pens in Western Lake were removed in 2007 due to the worst WQ (Figures 6 and 7). Consequently, the TN and TP decreased significantly but were still at the Class IV and V levels (Figure 9). At Stage V, the relevant governments continued to appeal that the pen aquaculture area was to be reduced to make a way for the health requirement of a good water ecology in Lake Yangcheng. Meanwhile, some measures that could control pollution and improve the WQ were also taken, such as controlling the amount of feeds, establishing ecological dams and limiting the pollutant discharge from surrounding watersheds [1]. As a result, the WQ was further improved from Class IV to Class III for TP and from Class V to Class IV for TN.

Therefore, local government measures were important driving factors of pen aquaculture decrease from Stage III to Stage V. Meanwhile, the TN and TP levels had significantly similar change patterns as the percentage of pen areas in the Central and Eastern Lakes from Stage III to Stage V (Figure 9). As shown in Figures 8 and A5, the government measures regarding removing and controlling pen aquaculture had an important positive effect on water quality in the Central and Eastern Lakes. 


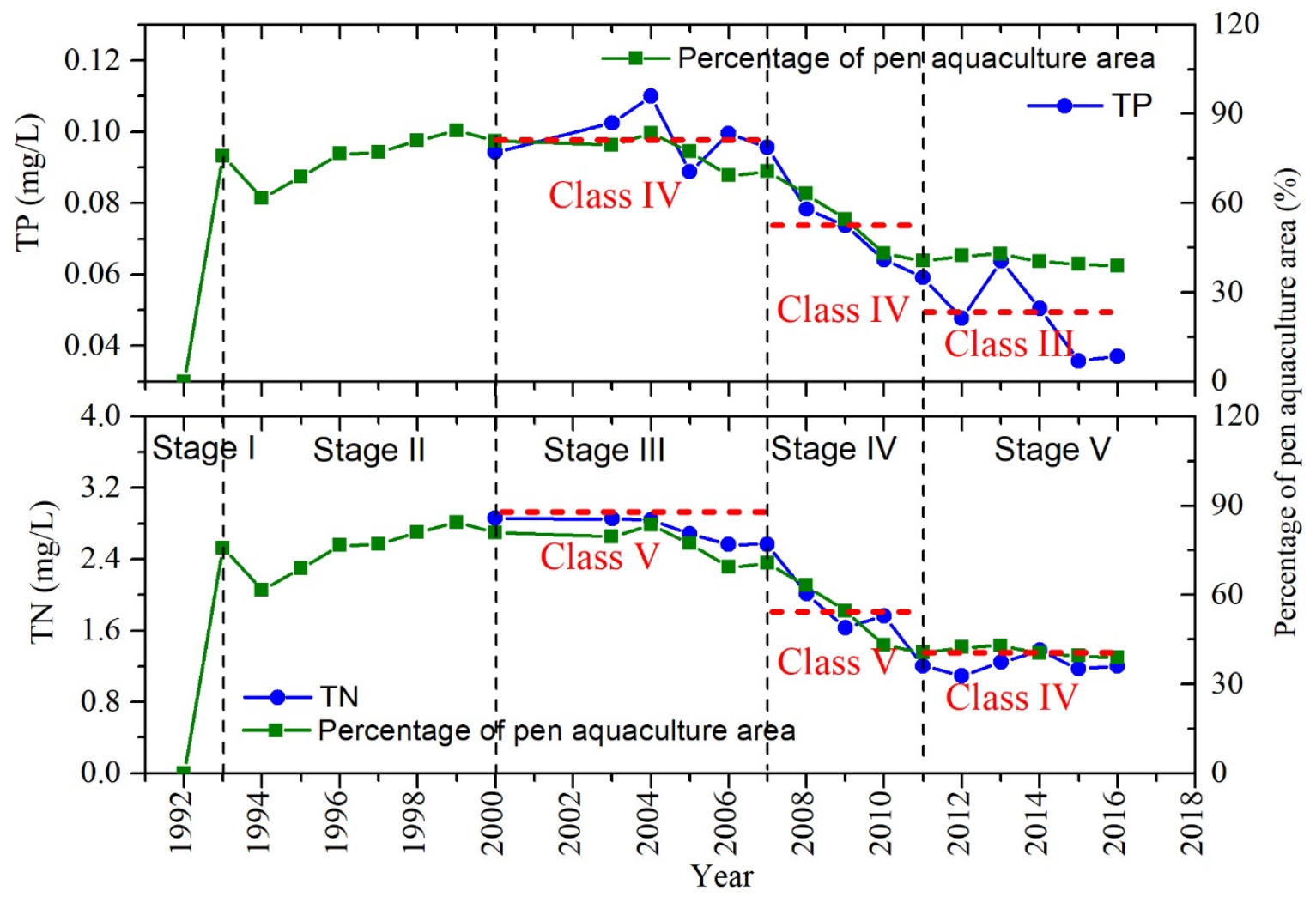

Figure 9. Changes in TN, TP and the percentages of pen area in the Central and Eastern Lakes. Due to the lack of WQ data in 2001 and 2002, pen aquaculture data in the two years were not shown in this figure.

\section{Conclusions}

In this study, an approach for automatically extracting pen aquaculture was first developed, and the accuracy of mapping pen aquaculture was higher than $92 \%$. Then, the spatial and area changes of pen aquaculture in Lake Yangcheng were mapped from 1992 to 2016. Through this study, several conclusions could be derived from our experimental results as follows:

(1) Given the high profit of CMC and local government measures, the pen aquaculture experienced five important stages, including Stage I (before 1993) without pen aquaculture, Stage II (1993-2001) with a sharp increase, Stage III (2001-2007) slightly decreasing, Stage IV (2007-2011) declining dramatically and Stage V (2011-2016) a relatively stable pen aquaculture.

(2) The percentage of pen aquaculture area exhibited significant positive correlations with $\mathrm{NH}_{3}-\mathrm{N}$, $\mathrm{TN}, \mathrm{Chla}, \mathrm{BOD}, \mathrm{COD}_{\mathrm{Mn}}$ and TP, but significant negative correlations with SDD and DO.

(3) The government regulations regarding controlling and removing pen aquaculture were effective, and the WQ has been significantly improved since 2008.

The analysis results offer practical guidance for the local government to manage pen aquaculture in Lake Yangcheng. Meanwhile, they could also present an important implication for managing pen aquaculture and promoting WQ for similar shallow lakes that have pen aquaculture expansion and water pollution problems, especially for those in eastern China.

Author Contributions: Conceptualization, J.L.; methodology, J.L. and Z.M.; validation, Z.S.; formal analysis, R.P.; investigation, X.W., X.L. and Z.P.; writing-original draft preparation, J.L.; writing-review and editing, R.P.; visualization, Z.S.; supervision, R.M.; funding acquisition, L.Z. All authors have read and agreed to the published version of the manuscript.

Funding: This research was funded by the National Key Research and Development Program of China, grant number 2016YFC0500201-05, National Natural Science Foundation of China, grant number 41971314 and the Strategic Priority Research Program of the Chinese Academy of Sciences, grant number XDA19030302. 
Acknowledgments: Acknowledgement for the data support from Lake-Watershed Sub Center, National Earth System Science Data Center, National Science \& Technology Infrastructure of China (http://lake.geodata.cn).

Conflicts of Interest: The authors declare no conflict of interest.

\section{Appendix A}

Table A1. Acquisition dates and sensors of satellite images used in this study for mapping pen aquaculture from 1992 to 2013.

\begin{tabular}{cccccccc}
\hline Year & Month & Day & Sensor & Year & Month & Day & Sensor \\
\hline 1992 & 4 & 20 & TM & 2005 & 4 & 8 & TM \\
1993 & 5 & 25 & TM & 2006 & 5 & 29 & TM \\
1994 & 5 & 12 & TM & 2007 & 4 & 27 & TM \\
1995 & 5 & 8 & TM & 2008 & 5 & 2 & TM \\
1996 & 5 & 1 & TM & 2009 & 5 & 29 & ETM \\
1997 & 5 & 4 & TM & 2010 & 5 & 24 & TM \\
1998 & 4 & 21 & TM & 2011 & 4 & 25 & TM \\
2000 & 5 & 20 & ETM & 2012 & 5 & 15 & HJ \\
2001 & 4 & 13 & TM & 2013 & 4 & 14 & OLI \\
2002 & 5 & 26 & ETM & 2014 & 4 & 23 & HJ \\
2003 & 5 & 13 & TM & 2015 & 5 & 22 & OLI \\
2004 & 5 & 23 & TM & 2016 & 4 & 22 & OLI \\
\hline
\end{tabular}

Note: TM = Landsat Thematic Mapper (TM), ETM+ = Enhanced Thematic Mapper Plus (ETM+), OLI = Landsat Operational Land Imager (OLI).

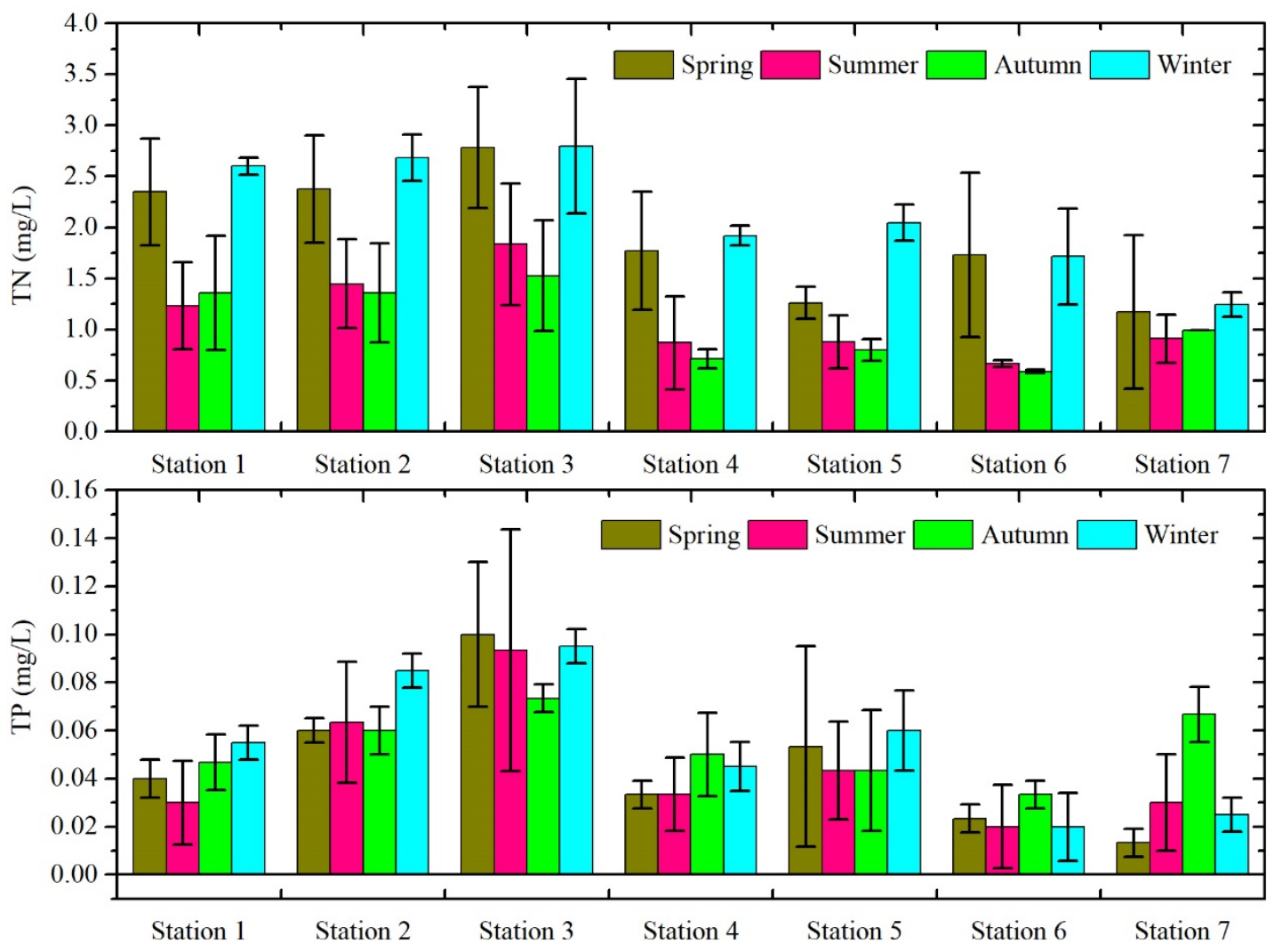

Figure A1. Seasonal variation in TN and TP at seven regular stations in 2016. 

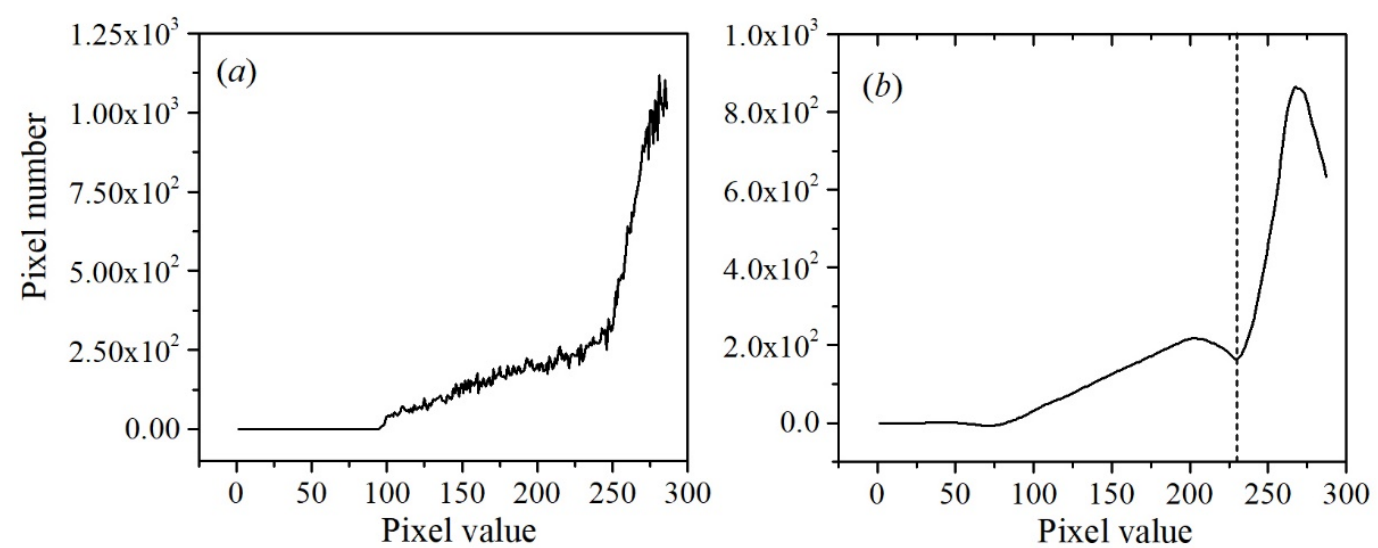

Figure A2. Histograms of grey level image (a) and wavelet reconstruction (b). The threshold was 231 according to Figure A2b, and all pixels with a value greater than 231 were counted as water in the DWT image.
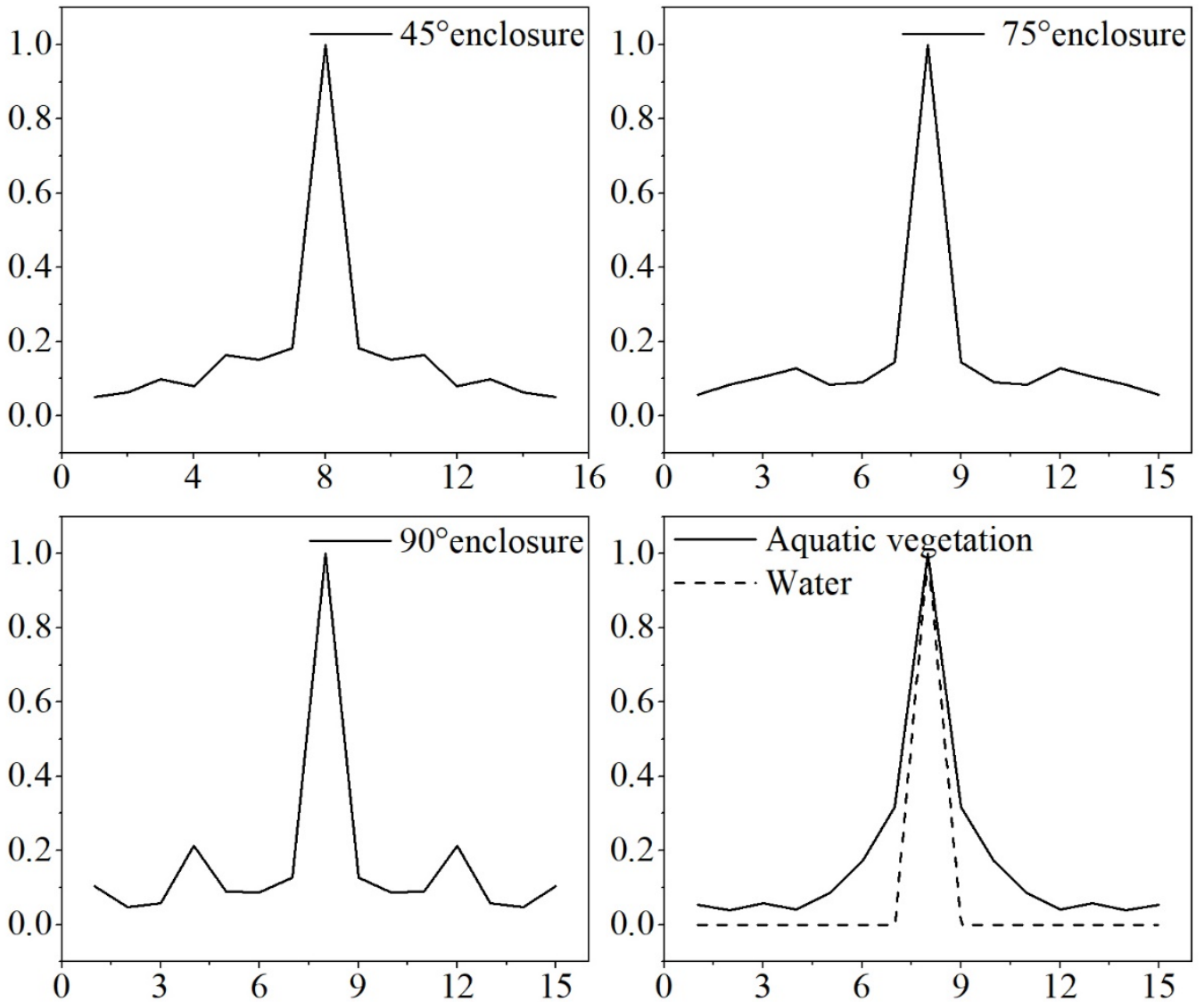

Figure A3. One-dimensional projections of FFT2 for $45^{\circ}, 75^{\circ}$ and $90^{\circ}$ pens, aquatic vegetation and water. Note that the $45^{\circ}, 75^{\circ}$ and $90^{\circ}$ enclosure represent the angles between pen facility and horizontal line. A pen facility area had distinct and periodical features compared with water and aquatic vegetation. 

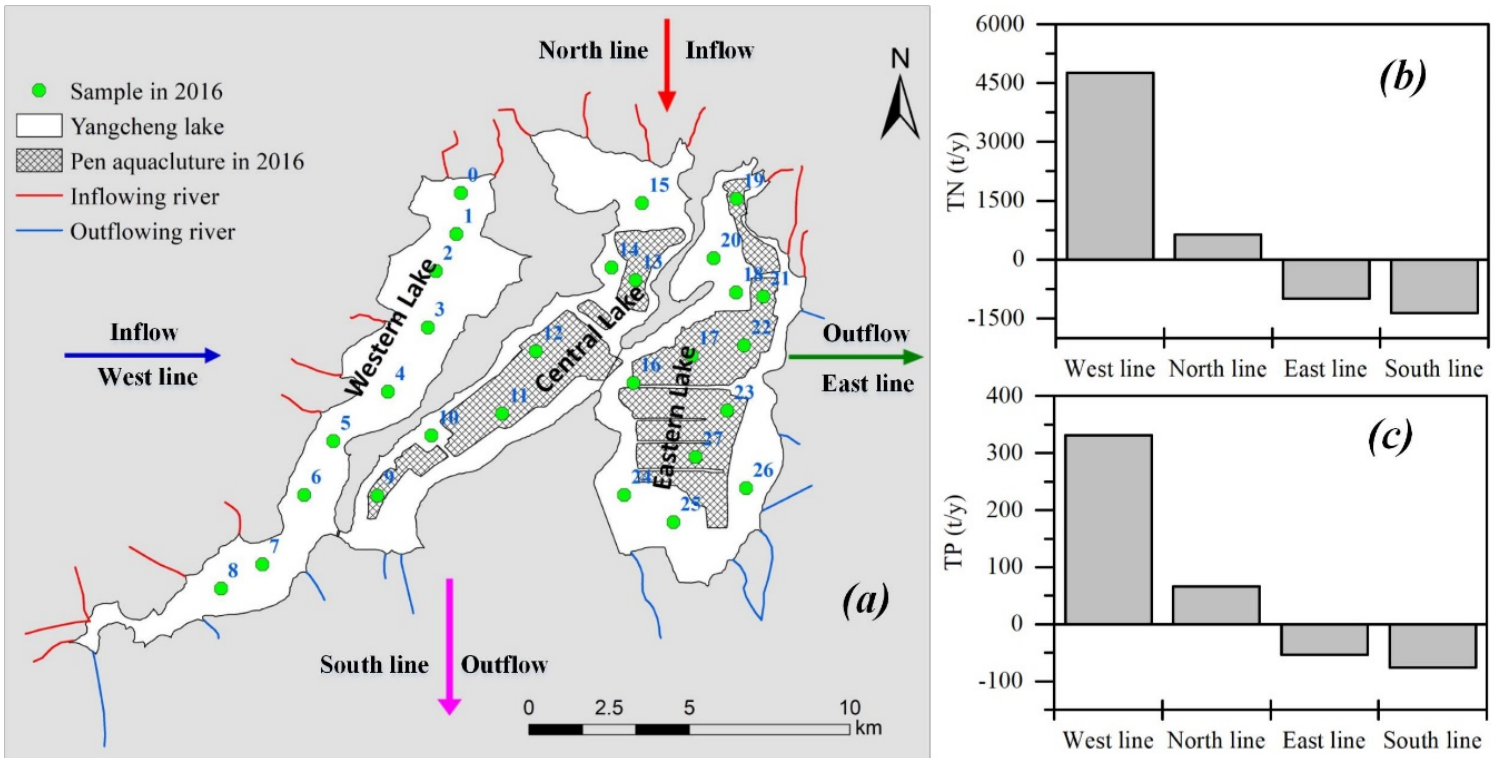

Figure A4. Distribution map of samples and pens in 2016 and inflowing and outflowing rivers (a); the amounts of inflowing or outflowing TN (b) and TP (c) in the West, North, East and South lines in 2016. A positive value represents the inflowing amount of TN or TP, and a negative value is the outflowing amount of TN or TP.
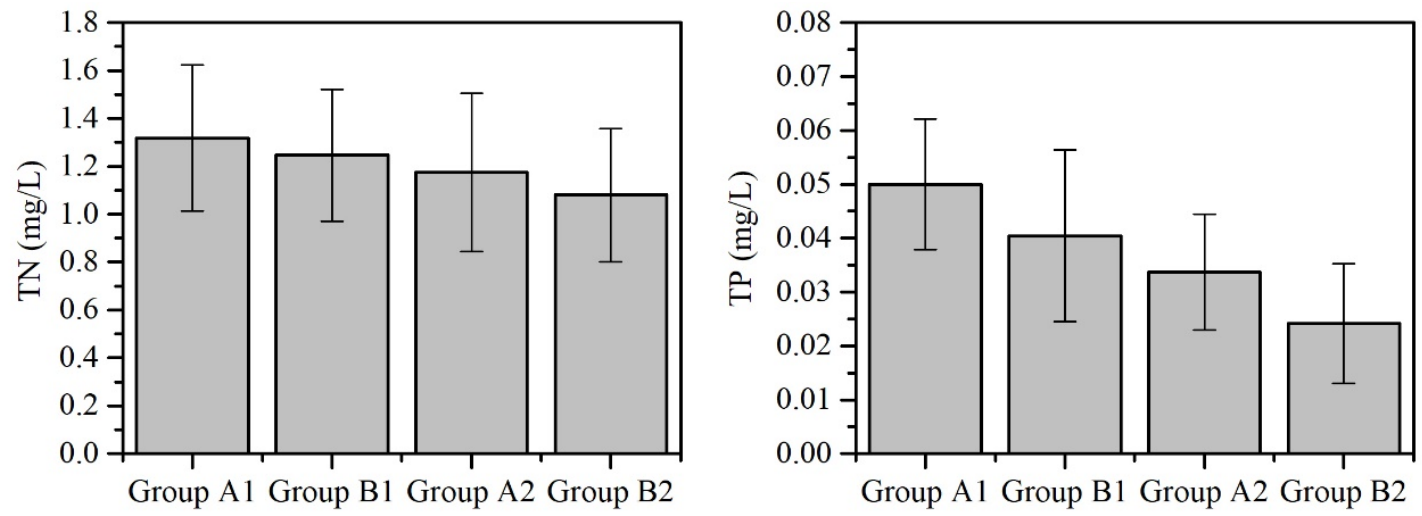

Figure A5. TN and TP concentrations in Groups A1, B1, A2 and B2. Group A1: the samples inside pens in Central Lake; Group A2: the samples inside pens in Eastern Lake; Group B1: the samples outside pens in Central Lake; Group B2: the samples outside pens in Eastern Lake.

\section{References}

1. Ni, Z.; Wu, X.; Li, L.; Lv, Z.; Zhang, Z.; Hao, A.; Iseri, Y.; Kuba, T.; Zhang, X.; Wu, W.-M.; et al. Pollution control and in situ bioremediation for lake aquaculture using an ecological dam. J. Clean. Prod. 2018, 172, 2256-2265. [CrossRef]

2. Song, X.; Wenbing, X.; Sun, L.; Guo, P.; Yang, C.; Gu, H. The Spatial and Temporal Changes of Nutrients of Net-pen Aquaculture Area in Yangcheng Lake and its Water Quality Evaluation. J. Hydroecol. 2010, 6. [CrossRef]

3. Edwards, P. Aquaculture environment interactions: Past, present and likely future trends. Aquaculture 2015, 447, 2-14. [CrossRef]

4. Tacon, A.G.; Metian, M.; Turchini, G.M.; De Silva, S.S. Responsible aquaculture and trophic level implications to global fish supply. Rev. Fish. Sci. 2009, 18, 94-105. [CrossRef]

5. Talbot, C.; Hole, R. Fish diets and the control of eutrophication resulting from aquaculture. J. Appl. Ichthyol. 1994, 10, 258-270. [CrossRef] 
6. Axler, R.; Larsen, C.; Tikkanen, C.; McDonald, M.; Yokom, S.; Aas, P. Water quality issues associated with aquaculture: A case study in mine pit lakes. Water Environ. Res. 1996, 68, 995-1011. [CrossRef]

7. Zang, C.; Huang, S.; Wu, M.; Du, S.; Scholz, M.; Gao, F.; Lin, C.; Guo, Y.; Dong, Y. Comparison of Relationships Between $\mathrm{pH}$, Dissolved Oxygen and Chlorophyll a for Aquaculture and Non-aquaculture Waters. Water Air Soil Pollut. 2010, 219, 157-174. [CrossRef]

8. Hu, Z.; Lee, J.W.; Chandran, K.; Kim, S.; Sharma, K.; Brotto, A.C.; Khanal, S.K. Nitrogen transformations in intensive aquaculture system and its implication to climate change through nitrous oxide emission. Bioresour. Technol. 2013, 130, 314-320. [CrossRef]

9. Liu, X.; Lu, S.; Guo, W.; Xi, B.; Wang, W. Antibiotics in the aquatic environments: A review of lakes, China. Sci. Total. Environ. 2018, 627, 1195-1208. [CrossRef]

10. Zhang, Y.; Ruan, X.; Wan, Y.; Li, X.J.G.J. Effects of environmental factors on anammox bacterial community structure in sediments of a freshwater aquaculture farm, Yangcheng Lake. Geomicrobiol. J. 2016, 33, 479-487. [CrossRef]

11. Chen, L.; Zhang, Y.; Liu, Q.; Hu, Z.; Sun, Y.; Peng, Z.; Chen, L. Spatial variations of macrozoobenthos and sediment nutrients in Lake Yangcheng: Emphasis on effect of pen culture of Chinese mitten crab. J. Environ. Sci. 2015, 37, 118-129. [CrossRef] [PubMed]

12. Cui, W.; Ning, B. Development and application of crab culture in the development of Chinese mitten crab industry of Shanghai. Aquac. Res. 2019, 50, 367-375. [CrossRef]

13. Wang, Q.; Cheng, L.; Liu, J.; Li, Z.; Xie, S.; De Silva, S.S. Freshwater aquaculture in PR China: Trends and prospects. Rev. Aquac. 2015, 7, 283-302. [CrossRef]

14. Chen, L.; Liu, Q.; Peng, Z.; Hu, Z.; Xue, J.; Wang, W. Rotifer community structure and assessment of water quality in Yangcheng Lake. Chin. J. Oceanol. Limnol. 2012, 30, 47-58. [CrossRef]

15. Li, X.; Li, J.; Wang, Y.; Fu, L.; Fu, Y.; Li, B.; Jiao, B. Aquaculture Industry in China: Current State, Challenges, and Outlook. Rev. Fish. Sci. 2011, 19, 187-200. [CrossRef]

16. Liu, H.; Fu, C.; Ding, G.; Fang, Y.; Yun, Y.; Norra, S. Effects of hairy crab breeding on drinking water quality in a shallow lake. Sci. Total Environ. 2019, 662, 48-56. [CrossRef]

17. Wang, Q.; Li, Z.; Lian, Y.; Du, X.; Zhang, S.; Yuan, J.; Liu, J.; De Silva, S.S.J.A. Farming system transformation yields significant reduction in nutrient loading: Case study of Hongze Lake, Yangtze River Basin, China. Aquaculture 2016, 457, 109-117. [CrossRef]

18. Mumby, P.J.; Green, E.P.; Edwards, A.J.; Clark, C.D. The cost-effectiveness of remote sensing for tropical coastal resources assessment and management. J. Environ. Manag. 1999, 55, 157-166. [CrossRef]

19. Gusmawati, N.; Soulard, B.; Selmaoui-Folcher, N.; Proisy, C.; Mustafa, A.; Le Gendre, R.; Laugier, T.; Lemonnier, H. Surveying shrimp aquaculture pond activity using multitemporal VHSR satellite images-Case study from the Perancak estuary, Bali, Indonesia. Mar. Pollut. Bull. 2018, 131, 49-60. [CrossRef]

20. Alexandridis, T.K.; Topaloglou, C.A.; Lazaridou, E.; Zalidis, G.C. The performance of satellite images in mapping aquacultures. Ocean Coast. Manag. 2008, 51, 638-644. [CrossRef]

21. Huang, W.; Fu, B. Remote Sensing for Coastal Area Management in China. Coast. Manag. 2002, 30, $271-276$. [CrossRef]

22. Pu, R.; Bell, S.; Meyer, C.; Baggett, L.; Zhao, Y. Mapping and assessing seagrass along the western coast of Florida using Landsat TM and EO-1 ALI/Hyperion imagery. Estuar. Coast. Shelf Sci. 2012, 115, 234-245. [CrossRef]

23. Luo, J.; Duan, H.; Ma, R.; Jin, X.; Li, F.; Hu, W.; Shi, K.; Huang, W. Mapping species of submerged aquatic vegetation with multi-seasonal satellite images and considering life history information. Int. J. Appl. Earth Obs. Geoinf. 2017, 57, 154-165. [CrossRef]

24. Jia, M.; Wang, Z.; Zhang, Y.; Mao, D.; Wang, C. Monitoring loss and recovery of mangrove forests during 42 years: The achievements of mangrove conservation in China. Int. J. Appl. Earth Obs. Geoinf. 2018, 73, 535-545. [CrossRef]

25. Villa, P.; Pinardi, M.; Bolpagni, R.; Gillier, J.-M.; Zinke, P.; Nedelcuţ, F.; Bresciani, M. Assessing macrophyte seasonal dynamics using dense time series of medium resolution satellite data. Remote Sens. Environ. 2018, 216, 230-244. [CrossRef]

26. Wang, M.; Cui, Q.; Wang, J.; Ming, D.; Lv, G. Raft cultivation area extraction from high resolution remote sensing imagery by fusing multi-scale region-line primitive association features. ISPRS J. Photogramm. Remote Sens. 2017, 123, 104-113. [CrossRef] 
27. Shi, T.; Zou, Z.; Shi, Z.; Chu, J.; Zhao, J.; Gao, N.; Zhang, N.; Zhu, X. Mudflat aquaculture labeling for infrared remote sensing images via a scanning convolutional network. Infrared Phys. Technol. 2018, 94, 16-22. [CrossRef]

28. Zheng, Y.; Duarte, C.M.; Chen, J.; Li, D.; Lou, Z.; Wu, J. Remote sensing mapping of macroalgal farms by modifying thresholds in the classification tree. Geocarto Int. 2018, 34, 1098-1108. [CrossRef]

29. Ren, C.; Wang, Z.; Zhang, Y.; Zhang, B.; Chen, L.; Xi, Y.; Xiao, X.; Doughty, R.B.; Liu, M.; Jia, M.; et al. Rapid expansion of coastal aquaculture ponds in China from Landsat observations during 1984-2016. Int. J. Appl. Earth Obs. Geoinf. 2019, 82, 101902. [CrossRef]

30. Murata, H.; Komatsu, T.; Yonezawa, C. Detection and discrimination of aquacultural facilities in Matsushima Bay, Japan, for integrated coastal zone management and marine spatial planning using full polarimetric L-band airborne synthetic aperture radar. Int. J. Remote Sens. 2019, 40, 5141-5157. [CrossRef]

31. Ottinger, M.; Clauss, K.; Kuenzer, C. Large-Scale Assessment of Coastal Aquaculture Ponds with Sentinel-1 Time Series Data. Remote Sens. 2017, 9, 440. [CrossRef]

32. Stiller, D.; Ottinger, M.; Leinenkugel, P. Spatio-Temporal Patterns of Coastal Aquaculture Derived from Sentinel-1 Time Series Data and the Full Landsat Archive. Remote Sens. 2019, 11, 1707. [CrossRef]

33. van der Werff, H.M.A.; van der Meer, F.D. Shape-based classification of spectrally identical objects. ISPRS J. Photogramm. Remote Sens. 2008, 63, 251-258. [CrossRef]

34. Zhang, T.; Yang, X.; Hu, S.; Su, F. Extraction of Coastline in Aquaculture Coast from Multispectral Remote Sensing Images: Object-Based Region Growing Integrating Edge Detection. Remote Sens. 2013, 5, 4470-4487. [CrossRef]

35. Virdis, S.G. An object-based image analysis approach for aquaculture ponds precise mapping and monitoring: A case study of Tam Giang-Cau Hai Lagoon, Vietnam. Environ. Monit. Assess. 2014, 186, 117-133. [CrossRef] [PubMed]

36. Loberternos, R.A.; Porpetcho, W.P.; Graciosa, J.C.A.; Violanda, R.R.; Diola, A.G.; Dy, D.T.; Otadoy, R.E.S. An Object-Based Workflow Developed to Extract Aquaculture Ponds from Airborne Lidar Data: A Test Case in Central Visayas, Philippines. ISPRS Int. Arch. Photogramm. Remote Sens. Spat. Inf. Sci. 2016, 41, 1147-1152. [CrossRef]

37. Zheng, Y.; Wu, J.; Wang, A.; Chen, J. Object- and pixel-based classifications of macroalgae farming area with high spatial resolution imagery. Geocarto Int. 2017, 33, 1048-1063. [CrossRef]

38. Wang, Y.; Hu, W.; Peng, Z.; Zeng, Y.; Rinke, K. Predicting Lake Eutrophication Responses to Multiple Scenarios of Lake Restoration: A Three-Dimensional Modeling Approach. Water 2018, 10, 994. [CrossRef]

39. Luo, J.; Li, X.; Ma, R.; Li, F.; Duan, H.; Hu, W.; Qin, B.; Huang, W.J.E.I. Applying remote sensing techniques to monitoring seasonal and interannual changes of aquatic vegetation in Taihu Lake, China. Ecol. Indic. 2016, 60, 503-513. [CrossRef]

40. Kronvang, B.; Jeppesen, E.; Conley, D.J.; Søndergaard, M.; Larsen, S.E.; Ovesen, N.B.; Carstensen, J. Nutrient pressures and ecological responses to nutrient loading reductions in Danish streams, lakes and coastal waters. J. Hydrol. 2005, 304, 274-288. [CrossRef]

41. Xing, Q.; Hu, C. Mapping macroalgal blooms in the Yellow Sea and East China Sea using HJ-1 and Landsat data: Application of a virtual baseline reflectance height technique. Remote Sens. Environ. 2016, 178, 113-126. [CrossRef]

42. Maini, R.; Aggarwal, H.J.C.S. A Comprehensive Review of Image Enhancement Techniques. Comput. Sci. 2010, 8-13.

43. Antoine, J.-P.; Carrette, P.; Murenzi, R.; Piette, B. Image analysis with two-dimensional continuous wavelet transform. Signal Process. 1993, 31, 241-272. [CrossRef]

44. Xiong, C.; Tian, J.; Liu, J. Efficient architectures for two-dimensional discrete wavelet transform using lifting scheme. IEEE Trans. Image Process. 2007, 16, 607-614. [CrossRef]

45. Lai, C.-C.; Tsai, C.-C. Digital Image Watermarking Using Discrete Wavelet Transform and Singular Value Decomposition. IEEE Trans. Instrum. Meas. 2010, 59, 3060-3063. [CrossRef]

46. Zhang, S.; Liu, J.; Wei, S.; Gao, J.; Wang, D.; Zhang, K. Impact of aquaculture on eutrophication in Changshou Reservoir. Chin. J. Geochem. 2006, 25, 90-96. [CrossRef]

47. Ma, L.; Crawford, M.M.; Tian, J. Local Manifold Learning-Based k-Nearest-Neighbor for Hyperspectral Image Classification. IEEE Trans. Geosci. Remote Sens. 2010, 48, 4099-4109. [CrossRef] 
48. Sun, S.; Chen, Q. Hierarchical Distance Metric Learning for Large Margin Nearest Neighbor Classification. Int. J. Pattern Recognit. Artif. Intell. 2012, 25, 1073-1087. [CrossRef]

49. Wang, J.; Sui, L.; Yang, X.; Wang, Z.; Liu, Y.; Kang, J.; Lu, C.; Yang, F.; Liu, B. Extracting Coastal Raft Aquaculture Data from Landsat 8 OLI Imagery. Sensors 2019, 19, 1221. [CrossRef]

50. Zhang, P.; Lv, Z.; Shi, W. Object-Based Spatial Feature for Classification of Very High Resolution Remote Sensing Images. IEEE Geosci. Remote Sens. Lett. 2013, 10, 1572-1576. [CrossRef]

51. Fu, Y.; Deng, J.; Ye, Z.; Gan, M.; Wang, K.; Wu, J.; Yang, W.; Xiao, G. Coastal Aquaculture Mapping from Very High Spatial Resolution Imagery by Combining Object-Based Neighbor Features. Sustainability 2019, 11, 637. [CrossRef]

52. Luo, J.; Ma, R.; Duan, H.; Hu, W.; Zhu, J.; Huang, W.; Lin, C. A New Method for Modifying Thresholds in the Classification of Tree Models for Mapping Aquatic Vegetation in Taihu Lake with Satellite Images. Remote Sens. 2014, 6, 7442-7462. [CrossRef]

53. Xiao, Z.; Liu, Q.; Tang, G.; Zhai, X. Elliptic Fourier transformation-based histograms of oriented gradients for rotationally invariant object detection in remote-sensing images. Int. J. Remote Sens. 2015, 36, 618-644. [CrossRef]

54. Corner, B.R.; Narayanan, R.M.; Reichenbach, S.E. Noise estimation in remote sensing imagery using data masking. Int. J. Remote Sens. 2010, 24, 689-702. [CrossRef]

55. Ma, X.; Li, Y.; Zhang, M.; Zheng, F.; Du, S. Assessment and analysis of non-point source nitrogen and phosphorus loads in the Three Gorges Reservoir Area of Hubei Province, China. Sci. Total Environ. 2011, 412-413, 154-161. [CrossRef] [PubMed]

(C) 2020 by the authors. Licensee MDPI, Basel, Switzerland. This article is an open access article distributed under the terms and conditions of the Creative Commons Attribution (CC BY) license (http://creativecommons.org/licenses/by/4.0/). 